\title{
Global Chassis Control System Using Suspension, Steering, and Braking Subsystems
}

\author{
Carlos A. Vivas-Lopez, ${ }^{1}$ Juan C. Tudon-Martinez, ${ }^{2}$ \\ Diana Hernandez-Alcantara, ${ }^{1}$ and Ruben Morales-Menendez ${ }^{1}$ \\ ${ }^{1}$ Tecnológico de Monterrey, School of Engineering and Sciences, Avenida E. Garza Sada No. 2501, 64849 Monterrey, NL, Mexico \\ ${ }^{2}$ Universidad de Monterrey, Avenida Ignacio Morones Prieto No. 4500, 66238 San Pedro Garza García, NL, Mexico \\ Correspondence should be addressed to Carlos A. Vivas-Lopez; a00794204@itesm.mx
}

Received 4 August 2015; Accepted 21 October 2015

Academic Editor: Xinggang Yan

Copyright (C) 2015 Carlos A. Vivas-Lopez et al. This is an open access article distributed under the Creative Commons Attribution License, which permits unrestricted use, distribution, and reproduction in any medium, provided the original work is properly cited.

\begin{abstract}
A novel Global Chassis Control (GCC) system based on a multilayer architecture with three levels: top: decision layer, middle: control layer, and bottom: system layer is presented. The main contribution of this work is the development of a data-based classification and coordination algorithm, into a single control problem. Based on a clustering technique, the decision layer classifies the current driving condition. Afterwards, heuristic rules are used to coordinate the performance of the considered vehicle subsystems (suspension, steering, and braking) using local controllers hosted in the control layer. The control allocation system uses fuzzy logic controllers. The performance of the proposed GCC system was evaluated under different standard tests. Simulation results illustrate the effectiveness of the proposed system compared to an uncontrolled vehicle and a vehicle with a noncoordinated control. The proposed system decreases by $14 \%$ the braking distance in the hard braking test with respect to the uncontrolled vehicle, the roll and yaw movements are reduced by $10 \%$ and $12 \%$, respectively, in the Double Line Change test, and the oscillations caused by load transfer are reduced by $7 \%$ in a cornering situation.
\end{abstract}

\section{Introduction}

A road vehicle has a conjunction of interconnected subsystems, such as brakes, steering, suspension, engine, and tires, which is difficult to be controlled [1]. These subsystems interact among them modifying their individual behavior and consequently the overall performance of the vehicle; these interactions could cause negative effects. For example, the way the suspension system is tuned can dramatically affect the performance of the steering system; a soft suspension affects the tire grip decreasing the ability of the vehicle to steer; if the suspension is too stiff, tires will hop causing loss of control. Additionally, all vehicle subsystems have a nonlinear behavior, making their coordination a complex task.

Normally, each vehicle subsystem has an independent control system to accomplish a specific objective. For example, the brake system has the Antilock Braking System (ABS) to prevent tires from locking during hard braking avoiding skidding and loss of control [2]. Also, it has the Electronic
Stability Control (ESC) which creates a turning moment using the brakes to prevent loss of control. Both control systems have conflicting principles, the ABS releases the brake pressure whereas the ESC generates an additional one. Table 1 summarizes the used acronyms in this document.

Studies in global trends aim towards achieving intelligent vehicles in upcoming years [3]. These vehicles are required to meet present and future state regulations related to efficiency, autonomy, ecology, safety, and comfort [4]. Particularly, the global automotive industry is paying special attention to safety systems that guarantee the integrity of occupants, pedestrians, and/or other drivers when an accident occurs. Even the newest safety features (Collision Mitigation or Line Keeping Systems) are oriented to prevent possible dangerous situations; the main topic of research refers to the systems that react against a dangerous situation [5].

These opportunities demand more of the actual Vehicle Control Systems (VCS). The standard solutions was to independently treat any new objective by adding a new VCS. 
TABle 1: Acronyms definition.

\begin{tabular}{|c|c|}
\hline Acronyms & Description \\
\hline $\mathrm{ABS}$ & Antilock Braking System \\
\hline AS & Active Steering \\
\hline AFS & Active Front Steering \\
\hline CDC & Continuous Damping Controller \\
\hline DC & Decentralized Controllers \\
\hline DL & Decision Logic \\
\hline DLC & Double Line Change \\
\hline DoF & Degree of Freedom \\
\hline DBC & Data-Based Controller \\
\hline EMB & Electromechanical Braking \\
\hline ESC & Electronic Stability Control \\
\hline $\mathrm{ECU}$ & Electronic Control Unit \\
\hline $\mathrm{FH}$ & Fish Hook \\
\hline FCS & Force control system \\
\hline $\mathrm{FL}$ & Fuzzy logic \\
\hline FIS & Fuzzy Inference System \\
\hline GCC & Global Chassis Control \\
\hline IVDC & Integrated Vehicle Dynamics Control \\
\hline$k-\mathrm{NN}$ & $k$-Nearest Neighbor \\
\hline LPV & Linear parameter varying \\
\hline $\mathrm{MBC}$ & Model-Based Controller \\
\hline MF & Membership Function \\
\hline PC & Principal Component \\
\hline PCA & Principal Component Analysis \\
\hline RMS & Root Mean Square \\
\hline $\mathrm{ROC}$ & Receiver operating characteristic \\
\hline SA & Semiactive \\
\hline SAS & Semiactive suspension \\
\hline SAP & Suspension Adjustment Plane \\
\hline SCS & Steering control system \\
\hline SISO & Single-Input Single-Output \\
\hline SMC & Sliding Mode Control \\
\hline TRC & Traction Control \\
\hline $\mathrm{UC}$ & Uncontrolled \\
\hline VCS & Vehicle Control System \\
\hline VDC & Vehicle Dynamics Control \\
\hline $4 \mathrm{WIB}$ & Four-Wheel Independent Braking \\
\hline 4WS & Four-Wheel Steering \\
\hline
\end{tabular}

This parallel architecture can lead to some drawbacks, for example, a VCS is normally designed to seek a specific goal, but when it interacts with other VCS the result could degrade the global performance, overruling the original objectives of the individual controllers due to inherent coupling effects. Since those controllers have to work simultaneously, they have their own information system and Electronic Control Unit (ECU) demanding more costs and space; that is, vehicle infrastructure and complexity increase [6].

The concept of GCC, also called Integrated Vehicle Dynamics Control (IVDC), proposes the coordinated integration of those different VCS to pursuit a common goal [7].
This integration offers (1) the ability to simultaneously control various subsystems, (2) the ability to coordinate the actions of individual subsystems regarding a general goal [8], and (3) the ability to share information from sensors and actuators (also functions) [9].

This concept has been investigated in the literature. The approaches can be differentiated regarding the number of Degrees of Freedom (DoF) in which they act (vertical, longitudinal, or lateral dynamics). Some cases have been studied as functional integrations (specific objective or single DoF). In [10], an integration of the braking and Semiactive (SA) suspension system is proposed to decrease braking distance in an emergency maneuver; but, in this case, there is no coordination. An integration of active suspension and braking is proposed in [11] to prevent a rollover situation using a Linear Parameter-Varying (LPV) controller driven by a scheduling parameter related to load transfer; the controller is highly model dependent.

Most of the research of this topic lays in the case of multipurpose integration (i.e., multiple DoF). An integration of steering and braking to enhance horizontal dynamics using robust control is proposed in [12]; however, the coordination algorithm and controller synthesis are not clear. In [13] the authors proposed a controller based on inversemodel dynamics to generate the desired control commands for braking and steering subsystems; the method is highly dependent in an accurate model of the system and sensitive to modeled dynamics. In [14] an integration of steering and braking systems is proposed. The goal is to maintain an optimum tire forces using Sliding Mode Control (SMC). It uses an optimization procedure to compute the optimum force distribution among the tires. In [15] a control strategy to improve the horizontal dynamics involving the braking and steering subsystems is proposed; it uses an optimization procedure to allocate the desired yaw moment; but, the cost functions have to be modified depending on the situation. In [16] a loss prevention control system is introduced using the braking and steering subsystems; this strategy relies on physical infrastructure in the road to calculate the reference signals, which nowadays is not available in most roads.

Only few works have been published on full dynamics integration (able to act in the vertical, longitudinal, and lateral dynamics). In [17], an integration of an active suspension, a 4-Wheel Steering (4WS), and a driving/braking force control using Traction Control (TRC) and ABS is proposed, but the coordination algorithm is not clear and the use of active suspension and 4WS is expensive. In [1], a strategy using the differential braking for horizontal dynamics and the active suspension for vertical is proposed; this method has to calculate the control command of each sampling time by optimization; this demands a lot of computational resources. The authors in [18] divide the problem; they treated vertical and horizontal dynamics separately. For vertical dynamics, it determines the desired force for each damper based on the LPV framework; but, its performance is fixed by design. For horizontal dynamics, it uses a gain scheduling parameter to decide when to apply braking control or a combination of steering with braking control. It defines some driving conditions (i.e., stable or unstable) but they are limited. The work 
of [19] proposed a control architecture capable of identifying the actual driving situation; based on the estimated situation, the control mode of each subsystem is changed. Even when this method is capable of reacting against different situations, it does not consider the switching implications in the control system, which could lead to unexpected behaviors. In [20], a control system based on LPV is proposed; in this case all three directions are simultaneously controlled using two varying parameters, one for suspension-steering and another for braking; however, the controller operates under predefined conditions without depending on the driving situation.

Although there are interesting results, they do not include the full dynamics integration; others are strongly modeldependent or they are robust to some uncertainty which could generate conservatism issues. Furthermore, some of them are not easy to implement in on-board Vehicle Dynamics Controllers.

The main contribution of this proposal lays in a new GCC system based on a discrimination of the operation conditions of the vehicle. The strategy architecture is a supervisory decentralized control to improve flexibility and modularity [21]. The goal is to identify the current driving situation, based on vehicle measurements using clustering methods [22]; then, the control modes of each subsystem are coordinated to ensure the best global performance. The coordination includes three subsystems: SAS, AFS, and 4-Wheel Independent Braking (4WIB), a full dynamics integration. The effectiveness of the new strategy was validated in CarSim.

The paper is organized as follows. Section 2 describes the problem. Section 3 presents the GCC architecture and modules in detail. Section 4 discusses the results, based on a case study. Section 5 concludes the research and proposes future work. Tables 2 and 3 summarize all the used variables in this work.

\section{Problem Description}

Passenger vehicles are equipped with a wide diversity of onboard VCS, and those focused on the management of the dynamical behavior of the vehicle are called Vehicle Dynamics Controllers (VDC), for example, Continuous Damping Controller (CDC) and Electronic Stability Control (ESC). Usually each VDC operates in a set of DoF defined by the vehicle reference system, Figure 1; the most important variables for each vehicle motion are as follows:

(i) Vertical dynamics refers to the movements that affect mainly the comfort of the passengers (vibration reductions); the important variables are pitch (turn around $y$-axis, $\phi$ ), roll (turn around $x$-axis, $\theta$ ), and vertical acceleration $(\ddot{z})$ in the Chassis and wheels.

(ii) Lateral dynamics refers mainly to the stability and handling (safety) of the vehicle; the important variables are lateral displacement $(y)$, side slip angle $(\beta)$, and yaw (turn around $z$-axis, $\psi$ ).

(iii) Longitudinal dynamics refers to vehicle stability (safety) and its performance (power train); the important variables are longitudinal velocity $\left(V_{x}\right)$, wheel rotational velocity $(\omega)$, and tire slip ratio $(\lambda)$.
TABLE 2: Modeling: variables description.

\begin{tabular}{|c|c|c|}
\hline Variable & Description & Units \\
\hline$a_{1}, a_{2}$ & $\begin{array}{l}\text { Hysteresis coefficients related to } \\
\text { displacement and velocity }\end{array}$ & $\mathrm{s} / \mathrm{m}, 1 / \mathrm{m}$ \\
\hline$c_{p}$ & Viscous damping coefficient & $\mathrm{Ns} / \mathrm{m}$ \\
\hline$f_{\text {brake }}, f_{\text {steer }}$ & $\begin{array}{l}\text { Cut-off frequency of the actuator } \\
\text { dynamics }\end{array}$ & $\mathrm{Hz}$ \\
\hline$f_{c}$ & $\begin{array}{l}\text { Force coefficient due to } \\
\text { manipulation }\end{array}$ & $\mathrm{N} / \mathrm{V}$ \\
\hline$F_{D}$ & Damper force & $\mathrm{N}$ \\
\hline$F_{\mathrm{SA}}$ & Semiactive damper force & $\mathrm{N}$ \\
\hline$k_{p}$ & Stiffness coefficient & $\mathrm{N} / \mathrm{m}$ \\
\hline$l$ & Vehicle wheel base & $\mathrm{m}$ \\
\hline$m_{s}, m_{\mathrm{us}}$ & Sprung/unsprung mass & $\mathrm{kg}$ \\
\hline$T_{b}^{+}, \delta^{+}$ & Actuator output & $\mathrm{MPa}$, deg \\
\hline$T_{b}^{*}, \delta^{*}$ & Actuator controller output & $\mathrm{MPa}$, deg. \\
\hline$V_{x}, v_{x_{i, j}}$ & Vehicle/tire longitudinal vel & $\mathrm{m} / \mathrm{s}$ \\
\hline$x, y, z$ & $\begin{array}{l}\text { Longitudinal/lateral/vertical } \\
\text { displacement }\end{array}$ & $\mathrm{m}$ \\
\hline$\dot{x}, \dot{y}, \dot{z}$ & $\begin{array}{l}\text { Longitudinal/lateral/vertical } \\
\text { velocity }\end{array}$ & $\mathrm{m} / \mathrm{s}$ \\
\hline$\ddot{x}, \ddot{y}, \ddot{z}$ & $\begin{array}{l}\text { Longitudinal/lateral/vertical } \\
\text { acceleration }\end{array}$ & $\mathrm{m} / \mathrm{s}^{2}$ \\
\hline$z_{\mathrm{def}}, \dot{z}_{\mathrm{def}}$ & Damper deflection and velocity & $\mathrm{m}, \mathrm{m} / \mathrm{s}$ \\
\hline$z_{r}, z_{s}, z_{\mathrm{us}}$ & $\begin{array}{l}\text { Road/sprung mass/unsprung } \\
\text { mass vertical position }\end{array}$ & $\mathrm{m}$ \\
\hline$\beta$ & Vehicle side slip angle & deg. \\
\hline$\delta$ & Steering wheel angle & deg. \\
\hline$\delta_{\text {driver }}$ & Driver's steering command & deg. \\
\hline$\lambda$ & Tire slip ratio & - \\
\hline$v$ & Damper manipulation & $\mathrm{V}$ \\
\hline$\phi, \theta, \psi$ & Pitch/roll/yaw angle & deg. \\
\hline$\dot{\phi}, \dot{\theta}, \dot{\psi}$ & Pitch/roll/yaw rate & deg./s \\
\hline$\dot{\psi}_{d}$ & Desired yaw rate & deg./s \\
\hline$\omega$ & Rotational speed of the tires & $\mathrm{rad} / \mathrm{s}$ \\
\hline
\end{tabular}

A VDC can have one or more of these three control goals: stability, handling, or vibration mitigation:

(1) Stability: when a vehicle has crossed its handling limits and tires lost their grip, it is said that the vehicle has become unstable and cannot be controlled by the action of the driver only; here, the main objective is to recover the driver's control to guarantee passengers safety.

(2) Handling: it refers to how well a vehicle can achieve cornering at high speeds; this condition is related to the safety characteristic of the vehicle.

(3) Vibration mitigation: it refers to the comfort that the passengers will experience during riding; this consists in the limitation of the unpleasant vibrations and movements caused by road irregularities; also, roadholding is considered, that is, vibration reduction in the unsprung mass at high vehicle velocities. 
TABLE 3: Algorithms: variables description.

\begin{tabular}{|c|c|}
\hline Variable & Description \\
\hline$a_{m}$ & Actuation vector \\
\hline$a_{u}$ & $\begin{array}{l}\text { Gain of the allocation } \\
\text { coordination }\end{array}$ \\
\hline$a_{u_{\text {susp }}}, a_{u_{\text {braking }}}, a_{u_{\text {steer }}}$ & $\begin{array}{l}\text { Suspension/braking/steering } \\
\text { coordination gain }\end{array}$ \\
\hline$c_{\min }, c_{\max }$ & $\begin{array}{l}\text { Softest/hardest damping } \\
\text { coefficient }\end{array}$ \\
\hline$C_{i}$ & Driving class \\
\hline $\operatorname{Con}_{i, k}$ & $\begin{array}{l}\text { Contribution index of the } i \text { th } \\
\text { variable in a } k \text { driving situation }\end{array}$ \\
\hline $\mathrm{CS}_{k}$ & $\begin{array}{l}\text { Minimal set of important } \\
\text { variables for a driving situation }\end{array}$ \\
\hline$d\left(x, y_{j}\right)$ & Euclidian distance \\
\hline$D_{C}$ & Driving situation \\
\hline$e(\beta), e(\dot{\psi})$ & Slip angle/yaw rate error \\
\hline$G_{\mathrm{ABS}}$ & ABS braking gain \\
\hline IS & Initial set of vehicle variables \\
\hline$k_{i}$ & Number of nearest neighbors \\
\hline$l_{k}$ & First $l$ principal components \\
\hline$m$ & Number of measurements \\
\hline MS & $\begin{array}{l}\text { Minimal set of important } \\
\text { variables for all driving situations }\end{array}$ \\
\hline$M_{z}$ & Corrective yaw moment \\
\hline$n, n^{*}$ & $\begin{array}{l}\text { Original/reduced number of } \\
\text { variables }\end{array}$ \\
\hline$r$ & Number of driving conditions \\
\hline$s_{s}$ & $\begin{array}{l}\text { Driving situation critical } \\
\text { condition }\end{array}$ \\
\hline$s_{i}$ & Driving situation importance \\
\hline$t_{\text {crit }}$ & Situation changing waiting time \\
\hline$t_{\text {con }}$ & Variable contribution threshold \\
\hline$T_{\text {driver }}$ & Driver braking torque \\
\hline$T_{\mathrm{ESC}_{r}}, T_{\mathrm{ESC}_{l}}$ & $\begin{array}{l}\text { Right/left corrective braking } \\
\text { pressure }\end{array}$ \\
\hline$T_{G}$ & Pressure gain \\
\hline$t_{n y}$ & Noise variance threshold \\
\hline$u_{c}, u_{c}^{*}$ & $\begin{array}{l}\text { Allocated/coordinated controller } \\
\text { output }\end{array}$ \\
\hline$\left.U\right|_{\mathrm{rh}},\left.U\right|_{\mathrm{conf}}$ & $\begin{array}{l}\text { Full suspension } \\
\text { road-holding/comfort } \\
\text { suspension command }\end{array}$ \\
\hline$u_{\text {susp }_{i, j}}, U_{\text {susp }}^{*}$ & $\begin{array}{l}\text { Single corner/full suspension } \\
\text { control command }\end{array}$ \\
\hline$x$ & Data point \\
\hline$X_{i_{\text {passive }}}, X_{i_{\text {controlled }}}$ & $\begin{array}{l}\text { Passive/controlled } i \text { th } \\
\text { performance variable }\end{array}$ \\
\hline$\tilde{x}_{i, k}$ & $\begin{array}{l}\text { Residual data point of the } i \text { th } \\
\text { measure in a } k \text { driving situation }\end{array}$ \\
\hline$\beta_{d}, \dot{\psi}_{d}$ & $\begin{array}{l}\text { Desired vehicle slip angle/yaw } \\
\text { rate }\end{array}$ \\
\hline$\delta_{\mathrm{AFS}}$ & Corrective steering angle \\
\hline$\delta_{\text {steering wheel }}^{*}, \delta_{\text {wheels }}^{*}$ & $\begin{array}{l}\text { Steering wheel/wheels } \\
\text { directional angle }\end{array}$ \\
\hline
\end{tabular}

TABLE 3: Continued.

\begin{tabular}{ll}
\hline Variable & Description \\
\hline$\lambda_{\text {crit }}$ & Critical tire slip ratio \\
$\sigma_{x_{i, k}}$ & Variance of the $i$ th variable in a $k$ \\
$\mathbf{R}_{k}$ & driving situation \\
$\mathbf{X}_{k}$ & Covariance matrix \\
$\widehat{\mathbf{P}}_{k}, \widetilde{\mathbf{P}}_{k}$ & Data matrix of $n$ variables \\
$\widehat{\mathbf{T}}_{k}, \widetilde{\mathbf{T}}_{k}$ & Principal/residuals components \\
$\widehat{\mathbf{X}}_{k}, \widetilde{\mathbf{X}}_{k}$ & matrix \\
$i$ & Principal/residual scores matrix \\
$k$ & Principal/residual transformed \\
$j$ & variables \\
\hline
\end{tabular}

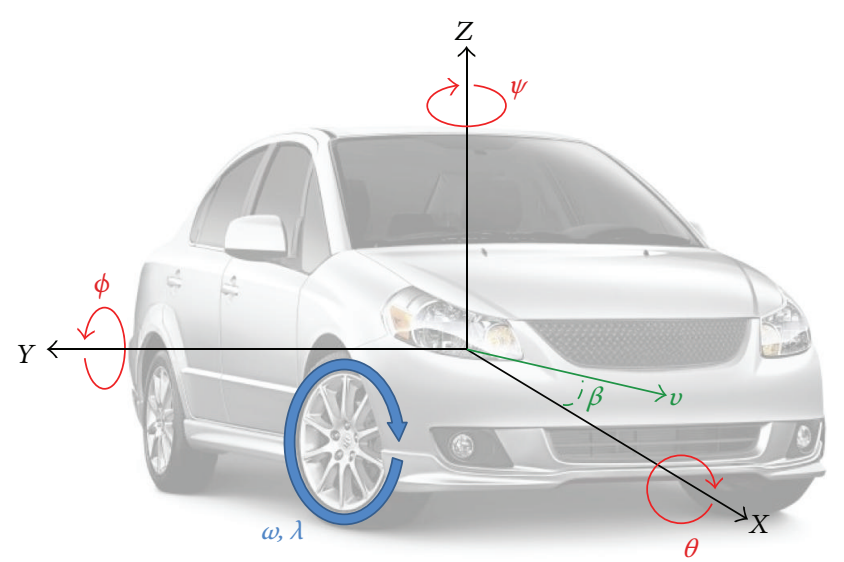

FIGURE 1: Vehicle reference system and important dynamical variables.

To develop a full dynamics integration in the vehicle it is necessary to control/coordinate the different subsystems simultaneously [17]. Usually the selected subsystems are (1) Active Front Steering, (2) Independent Braking, and (3) SAS. Another requirement is the use of different controllers acting in those subsystems depending on the current driving situation [23]; but, this feature leads to switching those controllers, which could cause unstability [24].

In road vehicles, the inherent coupling effects among their subsystems impact the overall performance of the vehicle. The coupled effects plus the issues that come with the interactions of different independent control systems increase the complexity of controlling the vehicle dynamics.

The above conditions can be handled with integrated control strategies, where subsystems and control actions are efficiently coordinated. Such strategies avoid contradictions in the control goals of the subsystems to obtain a better global performance from them at each situation [25]. Model-based control approaches represent a complex and unpractical solution, considering the vehicle as a highly nonlinear system. On the other hand, Data-Based Controllers could represent a reliable option in practice, assuming that the vehicle 


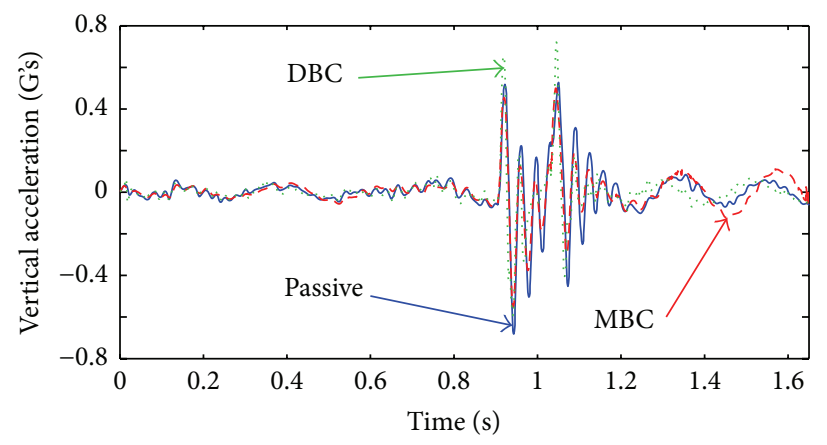

(a) Vertical acceleration $\left(\ddot{z}_{s}\right)$

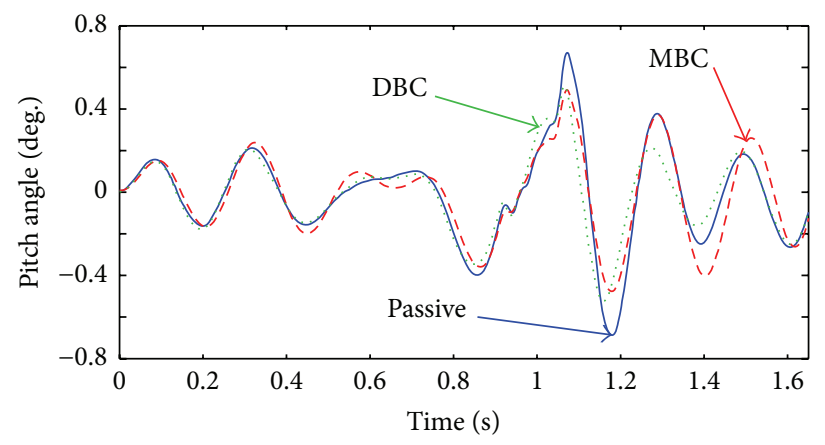

(b) Pitch angle $(\phi)$

Figure 2: Comparison of MBC and DBC approaches.

dynamics is monitored by some sensors. Figure 2 compares the two approaches under the road profile with bump test. This test is used to evaluate the road isolation characteristics of the control systems. Here 3 cases are compared: (1) Passive: a vehicle with nominal shock absorbers, (2) a Model-Based Controller (MBC): a full suspension $H_{\infty}$ controller designed to minimize the vertical acceleration $\left(\ddot{z}_{s}\right)$ and the pitch $(\phi)$ movements of the sprung mass, and (3) a Data-Based Controller (DBC): a controller that considers the classical SkyHook and Ground-Hook algorithms.

From Figure 2 it can be seen that the two approaches have a very similar performance. Quantitatively the MBC improved the vertical acceleration in $14.5 \%$ and the pitch movements in $9.74 \%$ with respect to the Passive case, whereas the DBC achieved an improvement of $9.1 \%$ and $17.8 \%$, respectively. Both approaches result in similar performances, but the DBC is simpler and faster to implement, compared to the $\mathrm{MBC}$ which has large dimension matrices inside the controller.

Based on the results of the literature review, VDC systems that achieve full dynamics integration are still a research topic.

\section{Global Chassis Control}

The architecture of the GCC system is divided into three main layers, Figure 3:

(1) Decision layer: it identifies the current driving situation and its stability; it decides how to coordinate the subsystems actions and their operating mode.

(2) Control layer: it receives the control goal from the decision layer and determines the proper orientation for each of the local controllers.

(3) Physical layer: it comprehends the actuators and sensors from the vehicle; it receives the control output from the control layer and sends the process variables from the sensors.

This multilayer and hierarchical architecture has some advantages: (1) it divides the computational load into several ECUs, (2) it allows information sharing, (3) it improves system flexibility (reconfigurability), and (4) it introduces

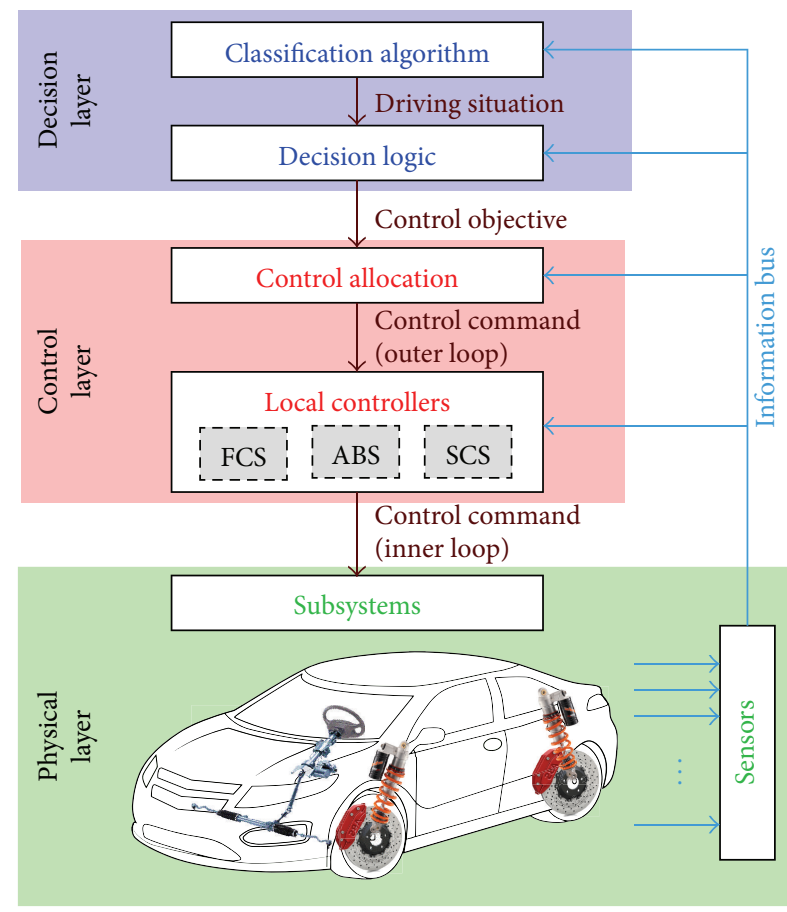

FIGURE 3: GCC architecture, hierarchical approach.

a modular scheme capability [26]. The information bus contains sensors measurements and actuators functions. Since the methods to observe or estimate the considered variables are not within the scope of this work, they are assumed to be available. Figure 4 shows a full scheme of the proposed GCC system.

3.1. Decision Layer. This layer has two main tasks: (1) classify the current driving situation and (2) coordinate the control strategy for the classified situation.

3.1.1. Classification Algorithm. The first step of the algorithm is to decide, from an Initial Set (IS) of variables, which is the Minimal Set (MS) to classify the current driving situation. The elements of IS must be variables that describe the global 


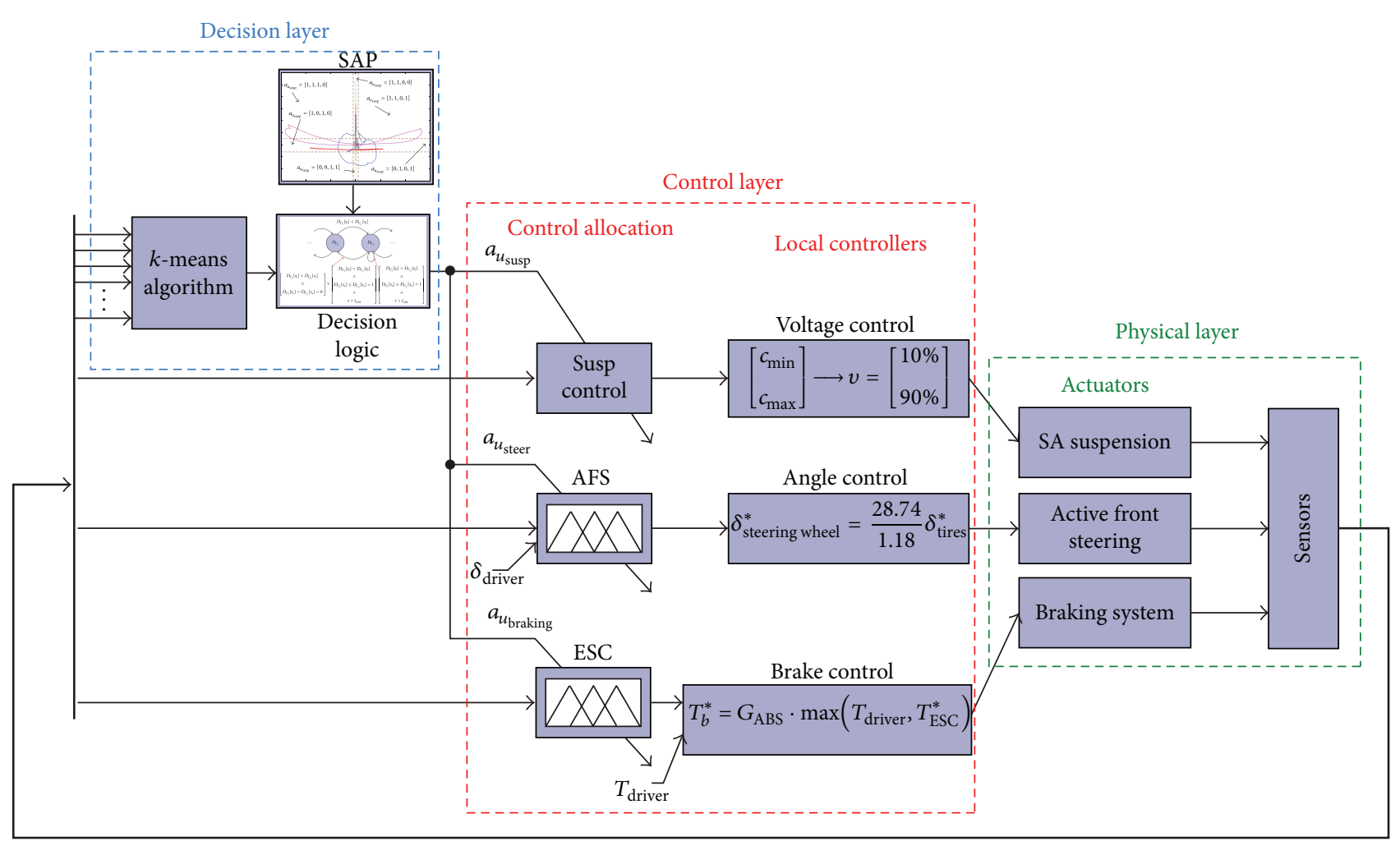

Sensors/actuators signals

FIgURE 4: Control scheme of the GCC system.

behavior of the vehicle, as well as variables that are commonly used in VCS:

$$
\text { MS } \subseteq \text { IS : }|\mathrm{MS}| \leq|\mathrm{IS}|
$$

Some vehicle variables are correlated; for example, pitch is correlated to deflections of the suspension. Besides, not all variables have the same importance in all driving situations; for example, in a riding situation the vertical acceleration will gain more importance, but during cornering yaw moment could be the most important. To determine the most representative vehicle variables during a driving situation, a Principal Component Analysis (PCA) is carried out.

Measurements of the variables in the IS set under different driving situations are used in this step, where $r$ is the number of driving situations to be considered, $\mathbf{X}_{k}$, with $k=$ $\{1,2, \ldots, r\}$, is the data matrix of $n$ variables, and $|\mathrm{IS}|=n$, and $m$ measurements, with zero mean and unit variance after a scaling process. To neglect the noise effect in the scaling process, variables with small variance are not considered; $\sigma_{x_{i, k}}<t_{n y}$, where $t_{n y}>0$ is a defined threshold.

Based on [27], $\widehat{\mathbf{P}}_{k} \in \mathfrak{R}^{n \times l_{k}}$ is obtained; it contains the first $l_{k}$ eigenvectors from the covariance matrix $\mathbf{R}_{k}$ and $\widetilde{\mathbf{P}}_{k} \in$ $\mathfrak{R}^{n \times\left(n-l_{k}\right)}$ which contains the last $l_{k}-n$ eigenvectors. The first $l_{k}$ eigenvectors associated with the $\mathrm{PC}$ have to explain at least $90 \%$ of the total variance of the original data for each driving situation. Then, the scores matrices $\widehat{\mathbf{T}}_{k} \in \mathfrak{R}^{m \times l_{k}}$ and $\widetilde{\mathbf{T}}_{k} \in$ $\mathfrak{R}^{m \times\left(n-l_{k}\right)}$ are obtained:

$$
\begin{aligned}
& \widehat{\mathbf{T}}_{k}=\mathbf{X}_{k} \widehat{\mathbf{P}}_{k}, \\
& \widetilde{\mathbf{T}}_{k}=\mathbf{X}_{k} \widetilde{\mathbf{P}}_{k} .
\end{aligned}
$$

By decomposing $\mathbf{X}_{k}=\widehat{\mathbf{X}}_{k}+\widetilde{\mathbf{X}}_{k}$ with

$$
\begin{aligned}
\widehat{\mathbf{X}}_{k} & =\widehat{\mathbf{T}}_{k} \widehat{\mathbf{P}}_{k}^{T}, \\
\widetilde{\mathbf{X}}_{k} & =\widetilde{\mathbf{T}}_{k} \widetilde{\mathbf{P}}_{\mathrm{k}}^{T},
\end{aligned}
$$

the modeled data is obtained with principal and residual components, respectively.

According to [28], using the residual components, $\widetilde{\mathbf{X}}_{k}$, the contribution of each variable $i$ can be obtained in each $k$ driving situation as

$$
\operatorname{Con}_{i, k}=\frac{\sum_{j=1}^{m} \tilde{x}_{i, k}^{2}(j)}{\sum_{i=1}^{n} \sum_{j=1}^{m} \tilde{x}_{i, k}^{2}(j)} \quad \forall i=\{1,2, \ldots, n\}
$$

Once the contributions are obtained, if $\operatorname{Con}_{i, k}>t_{\text {con }}$, then $\mathrm{Con}_{i, k} \mapsto \mathrm{CS}_{k}$, where $\mathrm{CS}_{k}$ is the set of the variables 


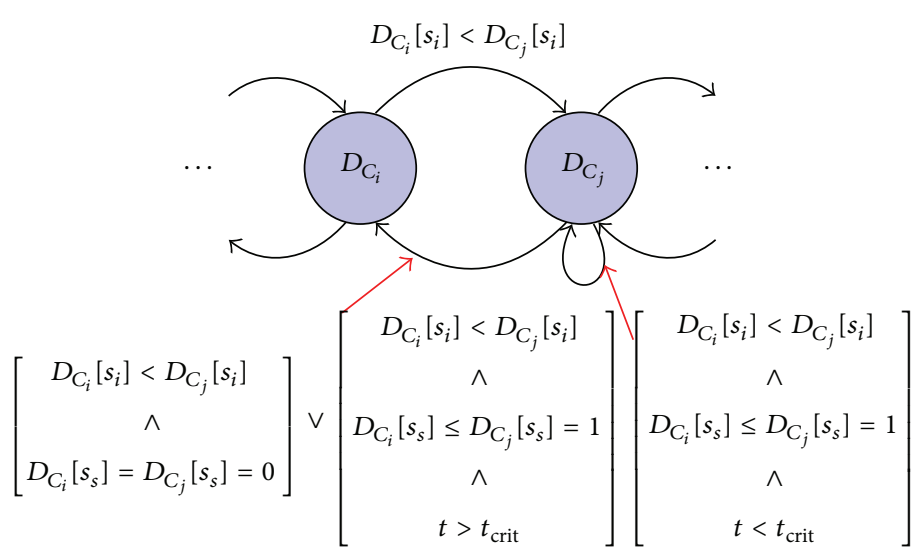

FIGURE 5: Graph for the DL module.

that contributes in each $k$ driving situation and $t_{\text {con }}>0$ is a defined threshold. Finally, the MS set is formed by

$$
\mathrm{MS}=\bigcup_{k=1}^{r} \mathrm{CS}_{k} \quad \forall k=\{1,2, \ldots, r\},
$$

with the resultant number variables equal to $|\mathrm{MS}|=n^{*}$.

After defining the MS set that contains the most representative variables for all studied driving situations, a clustering technique is exploited as classifier. Because of its easy computation, fast clustering response, and good performance, the $k$-Nearest Neighbor $(k-\mathrm{NN})$ algorithm was used.

The $k$-NN approach is one of the simplest machine learning algorithms, which it is based on the minimum distance criterion. A data set of reference patterns in a multidimensional feature space is required to establish the learning of this classifier, where the Euclidian distance is the most common metric. In this case, MS set contains the reference patterns of the studied driving situations.

Given a new data vector $x_{1}, x_{2}, \ldots, x_{n}$ of $n$ variables, the $k$-NN algorithm assigns each new observation into a class of driving situation $C_{i}$ according to

$$
x \in C_{i} \text { when } \min _{C} \frac{1}{k_{i}} \sum_{j=1}^{k_{i}} d\left(x, y_{j}\right),
$$

where $k_{i}$ is the number of nearest neighbors used in the classification associated with the driving situation $i$ and $d\left(x, y_{j}\right)$ is the Euclidian distance between a new observation $x$ and the nearest neighbors of reference defined by $y$. A large value of $k$ reduces the effect of noise in the classification; cross-validation can be used to define this parameter. For the vehicle, the sensor measurements contained in the MS set are used to construct the features space. The online result given by this clustering technique is sent to the Decision Logic (DL) module to classify the situation.

3.1.2. Decision Logic Module. Based on a set of heuristic rules, the DL module is in charge to decide (1) whether a driving situation is critical or normal, (2) if the control actions should change, and (3) when to change from one situation to another based on the importance of the previous situation.
First, the structure for a driving situation, $D_{C}$, must be defined. For this purpose, the DL module depends on the number of subsystems to use and the amount of driving situations, $r$, to consider. The definition of a $D_{C}$ is as follows:

(i) Each driving situation is defined with a vector in $\Re^{3}$ in the form: $D_{C}:=\left[s_{s}, s_{i}, a_{m}\right]$.

(ii) $s_{s} \in 0,1$ refers to normal $\left(s_{s}=0\right)$ or $\operatorname{critical}\left(s_{s}=1\right)$ situation.

(iii) $s_{i} \in 1, \ldots, q$ indicates the critical level of the driving situation: $s_{i} \rightarrow 1$ is a stable situation with negligible danger while $s_{i} \rightarrow q$ corresponds to the most dangerous condition.

(iv) $a_{m} \in \Re^{u}$ is the actuation vector for the $u$ subsystems that must be accomplished according to the detected driving situation; that is, $a_{m}=\left\{a_{1}, \ldots, a_{u}\right\}$. Considering an on-off control law for each subsystem, the control output is dichotomic $a_{i} \in[0,1]$.

Then, a set of rules that manage the transition between driving situations is defined. Figure 5 shows the graph diagram with the transition rules; the DL rules are carried as follows:

(1) A $D_{C}$ with bigger $s_{i}$ overrules a $D_{C}$ with a smaller $s_{i}$ index, and $a_{m}$ is updated.

(2) At any safe driving situation, independently of the $s_{i}$ index, the current $D_{C}$ updates the actuation vector $a_{m}$.

(3) In an unsafe driving situation, the current $D_{C}$ keeps the actuation vector in safe mode until the $s_{i}$ index decreases through the time $\left(t>t_{\text {crit }}\right)$ to ensure completely the vehicle safety and avoid any false alarms.

Finally, the DL layer sends the mode of operation of the subsystems controllers in the control layer.

3.2. Control Layer. This layer comprehends the control actions (allocation, manipulation) to be taken through the physical layer. The desired control allocation is determined based on the information received from the previous layer, and then the desired control manipulations are computed. 
3.2.1. Control Allocation. Based on the driving situation, the desired control action for each subsystem is defined in this sublayer. The control mode acts as a gain in the form of

$$
u_{c}^{*}=a_{u} \cdot u_{c}
$$

where $u_{c}^{*}$ is the controller output which depends directly on the gain of the coordinated allocation $a_{u}$; that is, $a_{u}=1$ means that the GCC demands the actuation on the subsystem, and vice versa (i.e., when $a_{u}=0$ ). Thus, $u_{c}$ is the local controller output of the subsystem obtained from any control law, but before the full dynamics integration. The allocation controllers for each subsystems are defined as follows.

(i) SAS. The SA dampers must always receive a manipulation; the decision is whether to select a manipulation oriented to comfort $\left(\left.U\right|_{\text {comf }}\right)$ or to road-holding $\left(\left.U\right|_{\text {rh }}\right)$ for each corner of the vehicle:

$$
U_{\text {susp }}^{*}=\left.\left(1-a_{u_{\text {susp }}}\right) \cdot U\right|_{\text {comf }}+\left.a_{u_{\text {susp }}} \cdot U\right|_{\text {rh }},
$$

where $U_{\text {susp }}^{*}=u_{\operatorname{susp}_{F, L}}, u_{\operatorname{susp}_{F, R}}, u_{\operatorname{susp}_{R, L}}, u_{\operatorname{susp}_{R, R}}$. Note that, according to the driving situation, the GCC can orient the suspension to comfort or to road-holding using the weighting parameter $a_{u_{\text {susp }}}$. At each corner, the SAS controller output can be oriented to comfort $\left(\left.u_{i, j}\right|_{\text {comf }}\right)$ or to road-holding $\left(\left.u_{i, j}\right|_{\mathrm{rh}}\right)$ inspired in the classical Sky-Hook and Ground-Hook control strategies:

$$
\begin{gathered}
\left.u_{i, j}\right|_{\mathrm{rh}}= \begin{cases}c_{\text {min }} & \text { if }-\dot{z}_{u s} \cdot \dot{z}_{\mathrm{def}} \leq 0 \\
c_{\max } & \text { if }-\dot{z}_{u s} \cdot \dot{z}_{\mathrm{def}}>0\end{cases} \\
\left.u_{i, j}\right|_{\text {comf }}= \begin{cases}c_{\text {min }} & \text { if } \dot{z}_{s} \cdot \dot{z}_{\text {def }} \leq 0 \\
c_{\max } & \text { if } \dot{z}_{s} \cdot \dot{z}_{\text {def }}>0,\end{cases}
\end{gathered}
$$

where $c_{\min }=0$ and $c_{\max }=1$ represent the softest and hardest damping coefficient, respectively.

(ii) Braking System. The braking action is computed by the fuzzy logic (FL) controller [29]. It uses two inputs: (1) side slip angle error $\left(e(\beta)=\beta-\beta_{d} \in[-10,10]\right)$ and (2) yaw rate error $\left(e(\dot{\psi})=\dot{\psi}-\dot{\psi}_{d} \in[-10,10]\right)$ and one output: (1) corrective yaw moment $\left(M_{z} \in[-1,1]\right)$. The control goal is to reduce the errors to zero; for this purpose the reference signals are defined as $\beta_{d}=0$, since the goal is to have $\beta$ as close to zero as possible and

$$
\dot{\psi}_{d}=\frac{V_{x}}{l} \delta_{\text {driver }}
$$

where $V_{x}$ is the longitudinal velocity of the vehicle, $l$ is the wheel base, and $\delta_{\text {driver }}$ is the drivers steering angle command.

For the two input variables, five fuzzy sets with triangular Membership Functions (MFs) were used for each variable: $\{e(\beta), e(\dot{\psi})\}=\{\mathrm{NB}, \mathrm{NS}, \mathrm{Z}, \mathrm{PS}, \mathrm{PB}\}$, whereas, for the output variable, seven fuzzy sets also with triangular MFs were used: $\left\{M_{z}\right\}=\{\mathrm{NB}, \mathrm{NM}, \mathrm{NS}, \mathrm{Z}, \mathrm{PS}, \mathrm{PM}, \mathrm{PB}\}$. Table 4 describes the

\begin{tabular}{|c|c|c|c|c|c|}
\hline \multirow{2}{*}{$e(\beta)$} & \multicolumn{5}{|c|}{$e(\dot{\psi})$} \\
\hline & NB & NS & $\mathrm{Z}$ & PS & $\mathrm{PB}$ \\
\hline NB & $\mathrm{PB}$ & $\mathrm{PB}$ & NS & NB & $\mathrm{NB}$ \\
\hline NS & $\mathrm{PB}$ & $\mathrm{PM}$ & NS & NM & $\mathrm{NB}$ \\
\hline $\mathrm{Z}$ & $\mathrm{PM}$ & PS & $\mathrm{Z}$ & NS & $\mathrm{NM}$ \\
\hline PS & $\mathrm{PB}$ & $\mathrm{PM}$ & PS & NM & $\mathrm{NB}$ \\
\hline $\mathrm{PB}$ & PB & PS & PS & NS & $\mathrm{NB}$ \\
\hline
\end{tabular}
meanings of the used linguistic terms and Table 5 shows
TABLE 4: Linguistic terms.

\begin{tabular}{lc}
\hline NB & Negative big \\
NMH & Negative medium high \\
NM & Negative medium \\
NMS & Negative medium small \\
NS & Negative small \\
Z & Zero \\
PS & Positive small \\
PMS & Positive medium small \\
PM & Positive medium \\
PMH & Positive medium high \\
PB & Positive big \\
\hline
\end{tabular}

TABLE 5: FL inference rules for the braking system.

the rules for the proposed FL controller. This FL controller uses a Mamdani Fuzzy Inference System (FIS).

To allocate the desired output for the braking local controllers, $M_{z}$ is transformed in terms of ESCs as

$$
\begin{aligned}
M_{z} & >0 \longrightarrow \text { Brake rear left wheel: } \\
T_{\mathrm{ESC}_{r}} & =0, T_{\mathrm{ESC}_{l}}=T_{G} \cdot M_{z} ; \\
M_{z} & =0 \longrightarrow \text { No added braking: } \\
T_{\mathrm{ESC}_{r}} & =0, T_{\mathrm{ESC}_{l}}=0 ; \\
M_{z} & <0 \longrightarrow \text { Brake rear right wheel: } \\
T_{\mathrm{ESC}_{r}} & =-T_{G} \cdot M_{z}, T_{\mathrm{ESC}_{l}}=0,
\end{aligned}
$$

where $T_{G}$ is a parameter that relates the corrective yaw moment $\left(M_{z}\right)$ and the brake pressure to be applied by the braking system.

Additionally, the coordinated allocation affects the action of the braking FL controller, including or ignoring it, using the value of $a_{u_{\text {braking }}}$ as a gain:

$$
T_{\mathrm{ESC}}^{*}=a_{u_{\text {braking }}} \cdot T_{\mathrm{ESC}} \cdot
$$

(iii) AFS System. For this subsystem the allocation decides to introduce or not the AFS control action, as

$$
\delta^{*}=\delta_{\mathrm{driver}}+a_{u_{\mathrm{steer}}} \cdot \delta_{\mathrm{AFS}},
$$

where $\delta^{*}$ is the desired steering wheel angle, $\delta_{\text {driver }}$ is the driver's command, and $\delta_{\mathrm{AFS}}$ is the compensation angle calculated by the AFS system. From (13), it can be seen 
TABLE 6: FL inference rules for the steering system.

\begin{tabular}{lcccccc}
\hline$\beta$ & $\delta_{\text {driver }}$ & NB & NS & Z & PS & PB \\
\hline \multirow{4}{*}{ Low } & NB & NS & NS & Z & PB & PB \\
& NS & NMS & NMS & Z & PMH & PMH \\
& Z & NM & NM & Z & PM & PM \\
& PS & NMH & NMH & Z & PMS & PMS \\
& PB & NH & NH & Z & PS & PS \\
\hline \multirow{6}{*}{ High } & NB & NH & NH & Z & PS & PS \\
& NS & NMH & NMH & Z & PMS & PMS \\
& Z & NM & NM & NS & PMS & PMS \\
& PS & NMS & NMS & NS & NS & NS \\
& PB & NS & NS & NS & NS & NS \\
\hline
\end{tabular}

that the driver's command is always considered, but the compensation angle is considered if $a_{u_{\text {steer }}}=1$ or not if $a_{u_{\text {steer }}}=$ 0 .

As for the braking system, the steering action is computed using a FL controller [30]. Three input variables were selected: (1) side slip angle $(\beta \in[-10,10])$, (2) yaw rate error $\left(e(\dot{\psi})=\dot{\psi}-\dot{\psi}_{d} \in[-10,10]\right)$, and (3) steering angle input $\left(\delta_{\text {driver }} \in[-10,10]\right)$, and one output: (1) steering correction angle $\left(\delta_{\mathrm{AFS}} \in[-5,5]\right)$. The FL controller is oriented to create a steering wheel angle correction that minimizes the yaw rate error; the desired yaw rate is calculated using (10).

For input $\beta$ two fuzzy sets with sigmoid MFs were used: $\beta=\{$ Low, High $\}$. For the other two input variables, five fuzzy sets with triangular MFs were used: $\left\{e(\dot{\psi}), \delta_{\text {driver }}\right\}=$ $\{\mathrm{NB}, \mathrm{NS}, \mathrm{Z}, \mathrm{PS}, \mathrm{PB}\}$, whereas, for the output variable, eleven fuzzy sets, also with triangular standard MFs, were used $\left\{\delta_{\mathrm{AFS}}\right\}=\{\mathrm{NB}, \mathrm{NMH}, \mathrm{NM}, \mathrm{NMS}, \mathrm{NS}, \mathrm{Z}, \mathrm{PS}, \mathrm{PMS}, \mathrm{PM}, \mathrm{PMH}$, $\mathrm{PB}\}$. Table 6 shows the rules for the proposed FL controller, whose linguistic definitions are given in Table 4.

3.2.2. Local Controllers. This sublayer contains the local controllers for each subsystem. These controllers are SingleInput Single-Output (SISO) and only interact with their particular subsystem. These controllers receive the desired set-point $u_{c}^{*}$ from the control allocation sublayer and are in charge of executing it. Also, these controllers have to be selected regarding the subsystem to control. The subsystem controllers for this strategy are the following:

(i) SAS: because the control command coming from the allocation step is binary, the force control system is defined as follows:

$$
\left[\begin{array}{l}
c_{\min } \\
c_{\max }
\end{array}\right]=\left[\begin{array}{l}
0 \\
1
\end{array}\right] \longmapsto v=\left[\begin{array}{l}
10 \% \\
90 \%
\end{array}\right],
$$

where $v$ is the manipulation delivered to the SA damper, (i.e., electric current, voltage, and duty cycle).

(ii) Steering: the command, in terms of tire angles, to transform it to a single gain controller is

$$
\delta_{\text {steering wheel }}^{*}=\frac{28.74}{1.18} \delta_{\text {tires }}^{*} \text {. }
$$

(iii) Braking: the local controller is an ABS; it modifies the desired command as

$$
T_{b}^{*}=G_{\mathrm{ABS}} \cdot \max \left(T_{\text {driver }}, T_{\mathrm{ESC}}^{*}\right),
$$

where $T_{\text {driver }}$ is the driver braking command, $T_{\text {ESC }}$ is the braking command from the allocation system, and $G_{\mathrm{ABS}}$ is the gain of the ABS that releases the tire when it is locked. This control law selects the maximum between the command coming from the allocation system and the command from the driver. The $G_{\mathrm{ABS}}$ gain is obtained by the function

$$
G_{\mathrm{ABS}_{i, j}}= \begin{cases}0 & \text { if } \lambda_{i, j} \geq \lambda_{\text {crit }} \\ 1 & \text { if } \lambda_{i, j}<\lambda_{\text {crit }}\end{cases}
$$

with

$$
\lambda_{i, j}=\frac{V_{x}-v_{x_{i, j}}}{V_{x}}
$$

where $\lambda_{i, j}$ is the slip ratio for each wheel. The operation of this ABS controller is guided by $\lambda$; if $\lambda$ grows beyond the admissible range $\left(\lambda_{\text {crit }}=0.1\right)$, the braking system releases the tire until it recovers grip and the slip ratio decreases to the admissible range, where the braking torque is again applied to the tire.

3.3. Physical Layer. The physical layer is integrated by the sensors and actuators of the SAS, AFS system, and 4WIB system.

3.3.1. Suspension System. The suspension system is composed of a linear spring and a SA shock absorber. The key element is the set of SA shock absorber, one at each corner, which needs to be modeled as a function of a manipulation signal $(v)$. The damper force $\left(F_{D}\right)$ is modeled as a function of the damper deflection $\left(z_{\text {def }}\right)$, deflection velocity $\left(\dot{z}_{\text {def }}\right)$, and manipulation signal [31]:

$$
F_{D}=c_{p}\left(\dot{z}_{\text {def }}\right)+k_{p}\left(z_{\text {def }}\right)+F_{\mathrm{SA}}
$$

where $F_{\mathrm{SA}}=v \cdot f_{c} \cdot \tanh \left(a_{1} \cdot \dot{z}_{\mathrm{def}}+a_{2} \cdot z_{\mathrm{def}}\right)$ is the SA force due to $v, c_{p}$ is a viscous damping coefficient, $k_{p}$ is a stiffness coefficient, and $a_{1}$ and $a_{2}$ are hysteresis coefficients due to velocity and displacement, respectively. The SA damping force at each damper is continuous from $[-10000,6000] \mathrm{N}$.

3.3.2. Steering System. A steer-by-wire Active Steering (AS) system is used to provide an additional steering angle for corrective purposes; the actuator model is given by [32]

$$
\dot{\delta}^{+}=2 \pi f_{\text {steer }}\left(\delta^{*}-\delta^{+}\right),
$$

where $f_{\text {steer }}=10 \mathrm{~Hz}$ is the cut-off frequency of the actuator dynamics, $\delta^{*}$ is the steering controller output, and $\delta^{+}$is the actuator output; the bounded limits of actuation are $\left[-5^{\circ},+5^{\circ}\right]$. 


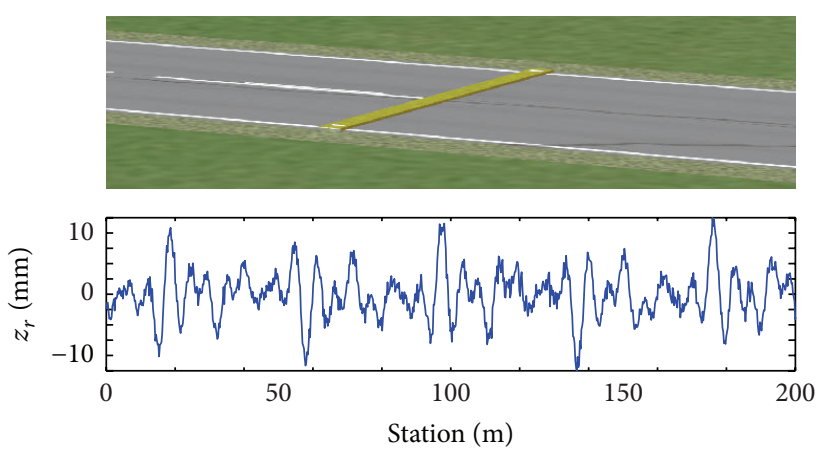

(a) Road profile with bump

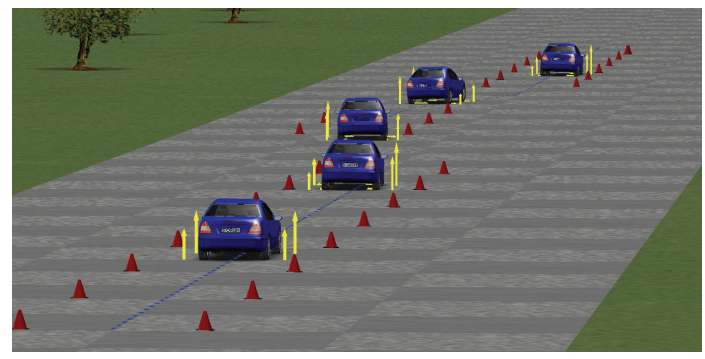

(c) DLC test (rapid steering)

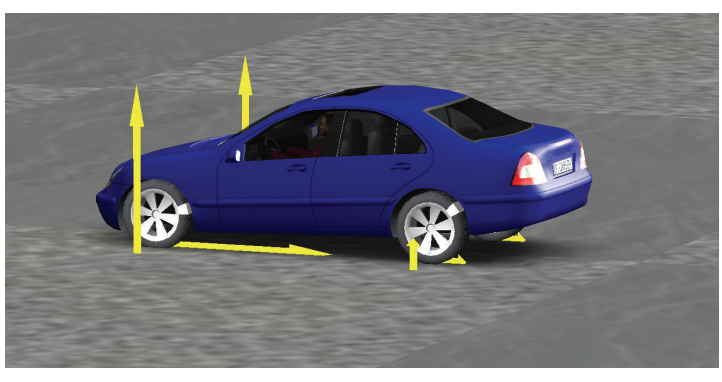

(b) Brake distance test (hard braking)

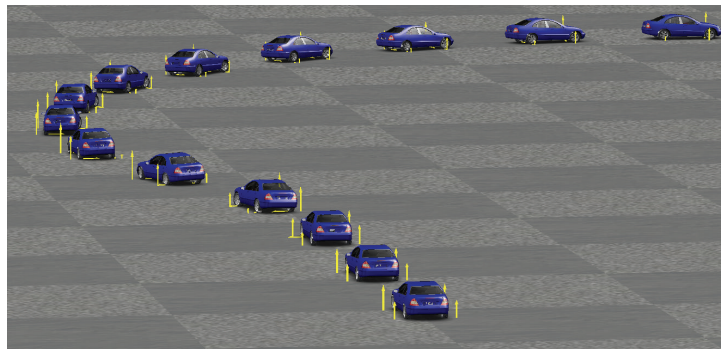

(d) FH test (cornering)

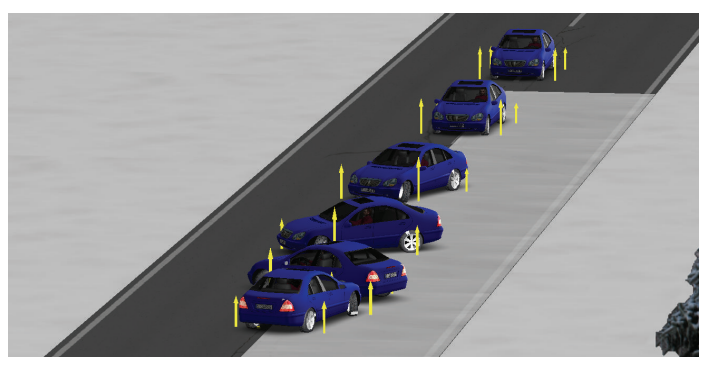

(e) Split $\mu$-surface braking (loss of vehicle control)

Figure 6: Implemented tests in CarSim.

3.3.3. Braking System. The corrective front and rear braking torques are provided by brake-by-wire Electromechanical Braking (EMB) actuators; the model of these EMB actuators is given by [32]

$$
\dot{T}_{b}^{+}=2 \pi f_{\text {brake }}\left(T_{b}^{*}-T_{b}^{+}\right),
$$

where $f_{\text {brake }}=10 \mathrm{~Hz}$ is the cut-off frequency of the actuator dynamics, $T_{b}^{*}$ is the braking controller output, and $T_{b}^{+}$is the actuator output. The bounded limits of actuation for each braking actuator are $[0,15] \mathrm{MPa}$.

\section{GCC System Evaluation}

The results of this proposal are presented based on a case study.

4.1. Case Study. CarSim was used to generate an accurate vehicle model whose VDC were hosted in Matlab/Simulink. A $D$-class sedan was the selected vehicle. Seven driving situations were considered $(r=7)$. Figure 6 illustrates some of the implemented tests to represent the driving situations; these tests are as follows:

(a) Road profile with bump test: this test is intended to evaluate the road isolation characteristics of the control strategy; it consists in a rough road with a sharp bump of $35 \mathrm{~mm}$ height and $400 \mathrm{~mm}$ length.

(b) Brake distance test: it consists in a hard braking action by the driver to measure the distance that takes the vehicle when it goes from $100 \mathrm{~km} / \mathrm{h}$ to a full stop.

(c) Double Line Change (DLC) maneuver: it consists in a change of driving line to simulate an obstacle avoidance maneuver or an overtaking action at high speed $(120 \mathrm{~km} / \mathrm{h})$; a rapid steering maneuver is taken by the driver to change from the original line, and then another rapid steering action to turn back to the original line.

(d) Fish Hook (FH) maneuver: this maneuver consists in a wide, but constant steering action; first a movement of $270^{\circ}$ of the steering wheel is taken to one side at a constant turning rate; then a turn of $540^{\circ}$ to 
TABLE 7: IS set.

\begin{tabular}{lcc}
\hline ID & Variable & Description \\
\hline $1-4$ & $z_{\text {def }_{i, j}}$ & Damper deflection \\
$5-8$ & $\dot{z}_{\text {def }_{i, j}}$ & Damper deflection rate \\
9 & $\phi$ & Pitch \\
10 & $\dot{\phi}$ & Pitch rate \\
11 & $\theta$ & Roll \\
12 & $\dot{\theta}$ & Roll rate \\
13 & $\psi$ & Yaw \\
14 & $\dot{\psi}$ & Yaw rate \\
15 & $\ddot{x}$ & Longitudinal acceleration \\
16 & $\ddot{y}$ & Lateral acceleration \\
17 & $\ddot{z}$ & Vertical acceleration \\
18 & $\beta$ & Vehicle slip angle \\
19 & $\dot{\beta}$ & Vehicle slip angle rate \\
20 & $\delta$ & Steering wheel angle \\
21 & $\dot{\delta}$ & Steering wheel angle rate \\
\hline
\end{tabular}

the opposite side is executed transferring the vehicle load from one side to another; then the steering angle is held to create a cornering situation which maintains the load transfer at a dangerous limit.

(e) Split $\mu$-surface braking test: the intention of this test is to evaluate how well a vehicle can keep its line during a braking action while riding with different friction coefficients in each side of the vehicle; this test is intended to cause loss of vehicle control from the driver.

4.2. Decision Layer. For space limitations, the results of the $\mathrm{DL}$ are presented just for the rapid steering driving situation.

4.2.1. Classification Algorithm. The IS set has a cardinality of $|\mathrm{IS}|=21$ elements (variables). Table 7 describes the considered variable set. These variables were selected because they describe completely the behavior of the vehicle.

Figure 7 shows the correlation level among the elements in the IS set, for the DLC test. Each square represents the level of correlation between two variables; for example, in the grid the principal diagonal shows a correlation of 1 (dark red) because it is the correlation of the variable with itself. A correlation of -1 (dark blue) indicates that the variable has an inverse correlation with the variable in question; for example, variable \#1 $\left(z_{\operatorname{def}_{F L}}\right)$ has a correlation of 1 with variable \#2 $\left(z_{\operatorname{def}_{R L}}\right)$ and a correlation of -1 with variable \#3 $\left(z_{\operatorname{def}_{F R}}\right)$. The above example can be interpreted as follows: during a roll situation, caused by the steering maneuver, the dampers of the same side (left) have the same compression whereas the dampers of the other side have the same movement, but in the opposite direction. It is notable that there is an inherent correlation among some variables, some of them can be neglected.

To find the MS set for this situation, the PCA algorithm was performed, Figure 8 . These results point out that only 4 PC could explain more than $90 \%$ of the total variance of

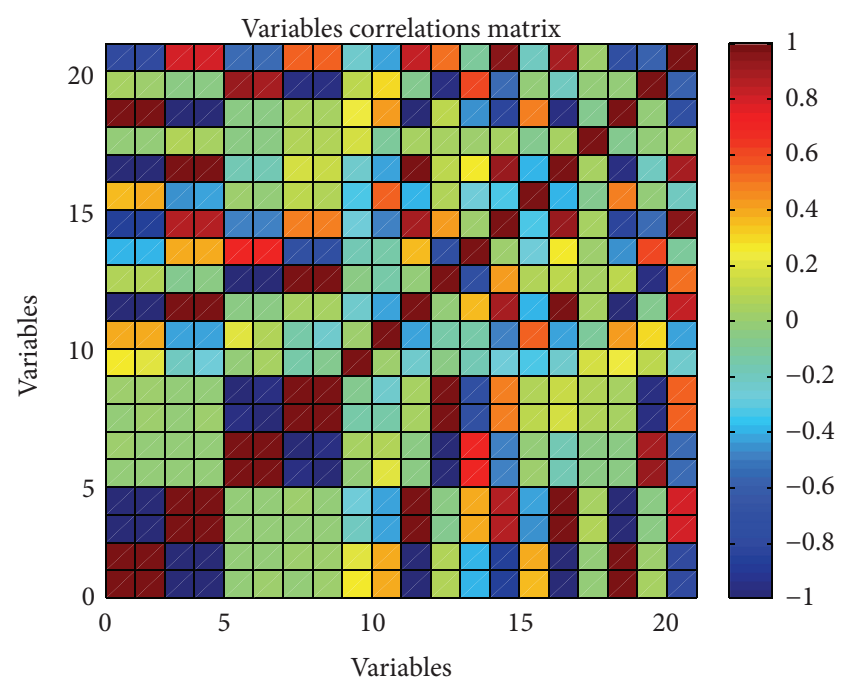

FIGURE 7: Correlation matrix of the IS set for a rapid steering driving situation.

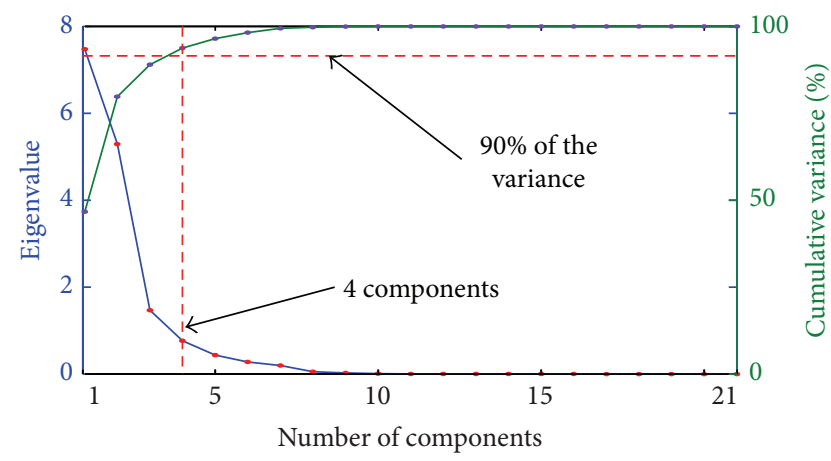

FIGURE 8: PCA result for the rapid steering situation.

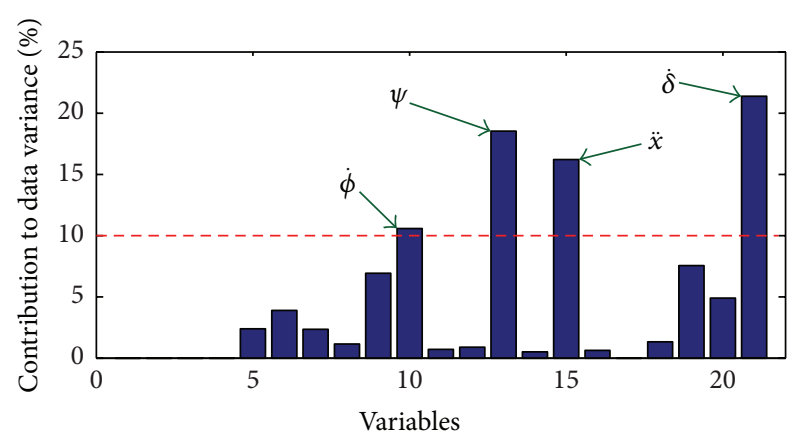

FIGURE 9: Contribution plot of the variables in the IS set.

the test. Figure 8 demonstrates that when the cumulative variance marker (green line) surpasses the $90 \%$ mark (horizontal red dotted line), the number of components is 4 .

It is important to relate the result with the IS set, such that the contribution of each variable to explain the total data variance can be studied in the residual space. Figure 9 shows the contribution of all variables for the DLC test. Those variables that overshoot the threshold $t_{\text {con }}=10 \%$ (red dotted 
TABLE 8: PCA results.

\begin{tabular}{lcccc}
\hline ID & Test & \# of PC & \% of explained variance & Variables in MS set \\
\hline 1 & Ride & 7 & 92.7 & $8,12,14,17,21$ \\
2 & Road irregularity & 4 & 90.2 & $9,10,17$ \\
3 & Acceleration/braking & 4 & 97.8 & $5,6,7,8,10$ \\
4 & Hard braking & 5 & 97.5 & $5,6,7,8,10$ \\
5 & Cornering & 7 & 93.1 & $10,13,18,20$ \\
6 & Rapid steering & 4 & 93.7 & $10,13,15,21$ \\
7 & Loss of control & 7 & 92.6 & $13,14,18,19$ \\
\hline
\end{tabular}

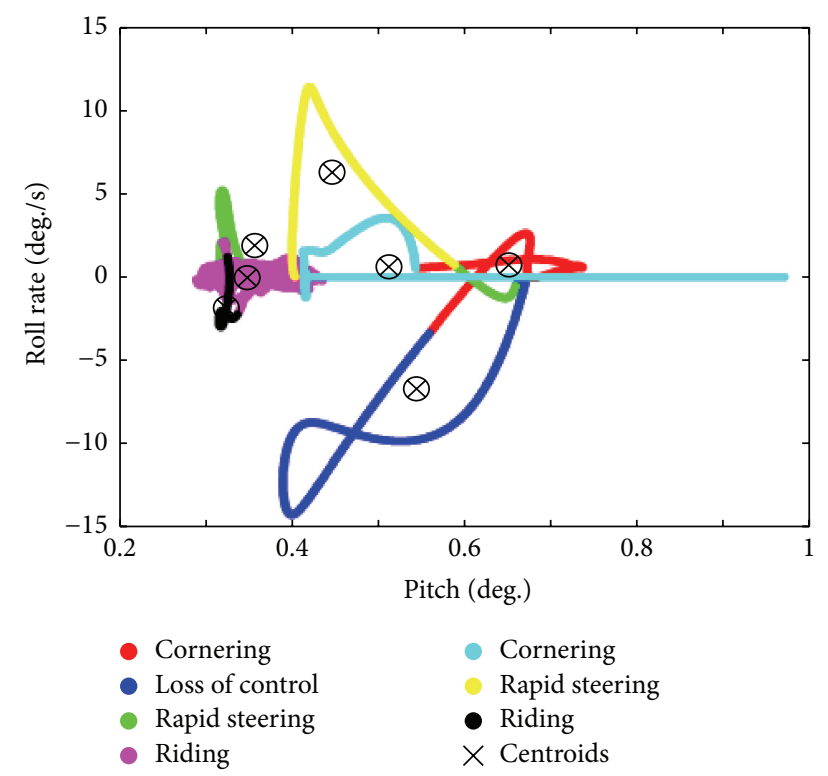

FIgURE 10: Clustering distribution for 2 dimensions.

line) are considered the most representative variables in this driving situation; they integrate the MS set.

Table 8 presents the PCA results for the seven driving situations. It can be concluded that the minimum set of variables for identifying any driving situation in MS = $\{5-10,12-15,17-21\}$. Once MS set is defined, the clustering step runs.

A $k$-NN classifier with $k=7$ was trained to classify 4 major driving situations (riding, cornering, rapid steering, and loss of control), where the first four tests in Table 8 are tagged as riding situation. Figure 10 shows the clusters distribution in 2D (pitch angle versus roll rate); note that clusters are differentiated by color. More than one cluster determine one of the four driving conditions: a cornering situation uses two clusters (red and cyan cluster).

To evaluate the classifier performance, a test, with a series of different driving situations, was designed. The test begins with the vehicle being driven in a rough road $\left(D_{C}=1\right)$; afterwards it has a rapid steering maneuver $\left(D_{C}=6\right)$; once the DLC maneuver passes and the vehicle is stabilized again, the test finishes with a cornering action $\left(D_{C}=5\right.$, FH maneuver). Figure 11 shows the target as well as the classification result for this test. This test was selected because

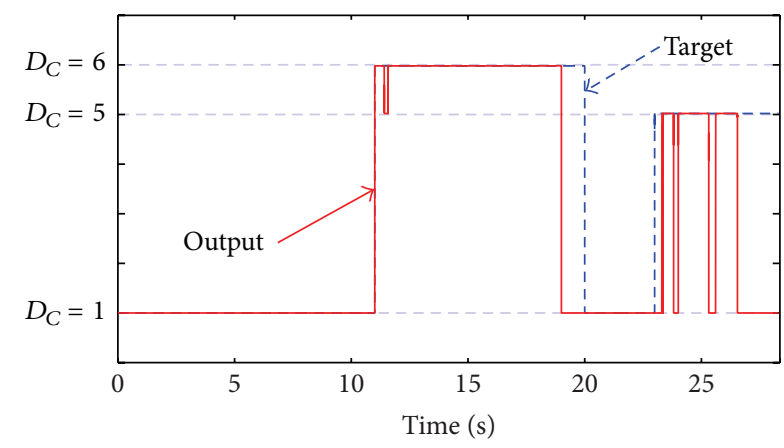

FIGURE 11: Validation test for the $k$-NN classifier.

the two conditions $\left(D_{C}=5\right.$ and $\left.D_{C}=6\right)$ are really similar in essence: both include steering action, but the difference lays in the velocity of the steering movement. From Figure 11, it is clear that rapid steering action is well detected by the classifier, but cornering has some drawbacks. During the rapid steering situation, some variables related to the vertical and lateral dynamics are highly sensitive, but during cornering the steady behavior of some movements is misjudged as riding conditions.

Figure 12 presents the ROC of the classifier results for the test in Figure 11. The riding situation is well classified, with a false alarm rate of $20 \%$. For the other two situations, the false alarm is zero but the detection error is $10 \%$ because of the rapid steering situation, while the cornering condition has the worst identification performance (error of 50\%).

From the previous analysis it can be concluded that the situations that involve roll and yaw movements can be well classified, but other driving situations (road irregularity, acceleration/braking, and hard braking) which are mostly pitch related can not be classified since all other driving situations also involve pitch movement.

To assist the $k$-NN classifier, a Suspension Adjustment Plane (SAP) was designed. SAP studies the vertical load transfer caused by vehicle movements, to adjust the SAS system. Its objective is to select the suspension settings depending on which area of the plane the vehicle is in. For example, if the vehicle is in a frontal pitch situation (braking) the system sets the two front dampers in road-holding mode, since most of the load is transferred to those tires. The same happens with a roll movement where the tires of the same side receive most of the load. The center area (between the red dotted lines) of the SAP is concerned with a normal riding situation. This area 


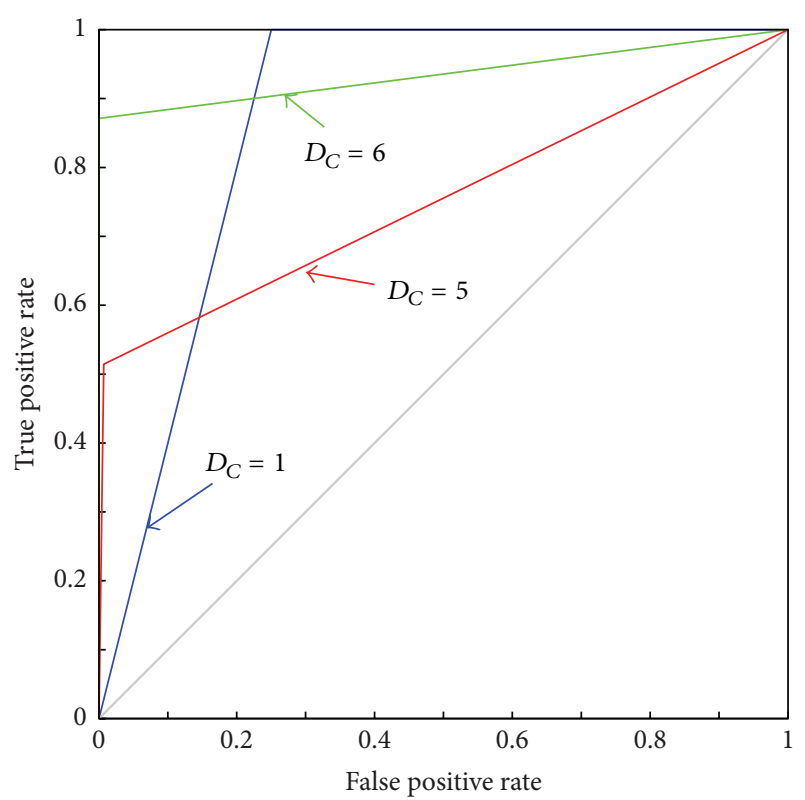

FIgURe 12: ROC for the $k$-NN classifier.

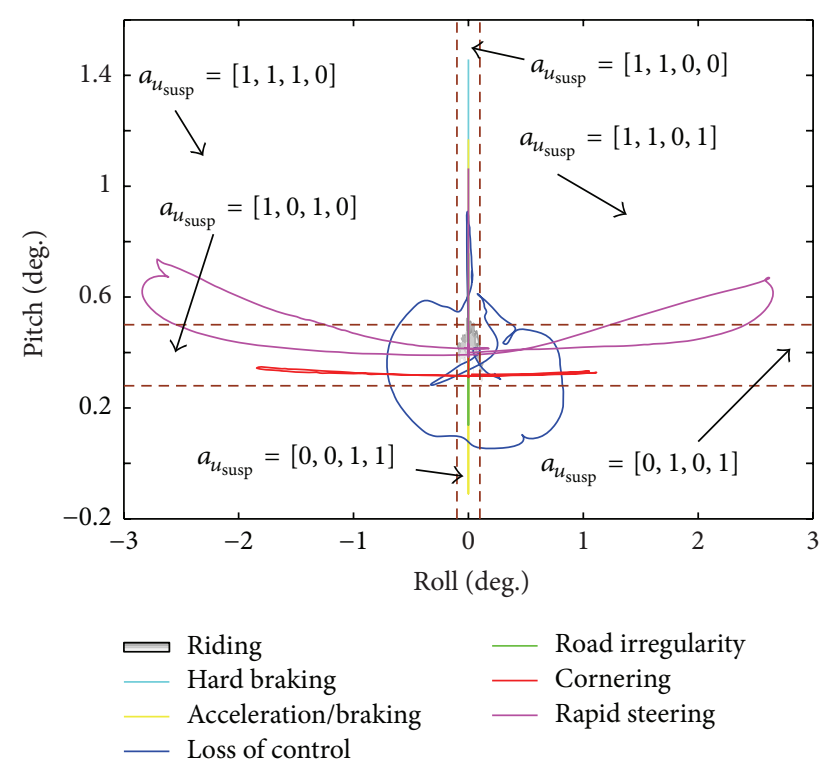

FIgure 13: Suspension Adjustment Plane (SAP).

was defined by considering different riding conditions (road roughness and velocities). Figure 13 shows the SAP with different driving situations and also the proper suspension combinations are marked for each region. With this plane it is possible to classify which riding situation occurs (riding per se, a road irregularity, an acceleration/braking situation, or a hard braking).

In Figure 13, the dotted lines delimit the threshold for pitch and roll movements caused by road roughness; outside those limits it is considered that the experienced movements are caused by other driving situations. The central vertical zone includes primarily pitch situations, like braking,
TABLE 9: $D_{C}$ vectors for different driving conditions.

\begin{tabular}{lccccc}
\hline Driving situation & \multicolumn{5}{c}{$D_{\mathrm{C}}$} \\
& $s_{i}$ & $s_{s}$ & $a_{u_{\text {susp }}}$ & $a_{u_{\text {steer }}}$ & $a_{u_{\text {braking }}}$ \\
\hline Ride & 1 & 0 & {$[0,0,0,0]$} & 0 & 0 \\
Road irregularity & 2 & 0 & SAP & 0 & 0 \\
Acceleration/braking & 3 & 0 & SAP & 0 & 0 \\
Hard braking & 4 & 0 & SAP & 0 & 0 \\
Cornering & 5 & 0 & SAP & 1 & 0 \\
Rapid steering & 6 & 1 & SAP & 1 & 1 \\
Loss of control & 7 & 1 & {$[1,1,1,1]$} & 1 & 1 \\
\hline
\end{tabular}

whereas the horizontal central zone refers to primarily roll movements like cornering.

4.2.2. Decision Logic. Table 9 presents the proposed values for vector $D_{C}$ at each driving situation.

4.3. Control Layer. The performance of the proposed GCC system is evaluated and compared with two additional control cases. The first case corresponds to an uncontrolled (UC) system; that is, it is a vehicle which lacks any control system and is equipped with standard actuators and a passive suspension system. The second case corresponds to a vehicle with a set of dynamics controllers without a coordination strategy in Decentralized Controllers (DC); that is, a set of controllers are acting simultaneously seeking their own control goals.

To evaluate quantitatively the performance at each driving test, the Root Mean Square (RMS) value of the signals is used. To have a point of comparison the RMS values of the controlled cases (DC and GCC) are normalized with that obtained by the UC case using

$$
\begin{aligned}
& \% \text { of Improvement } \\
& =\frac{\operatorname{RMS}\left(X_{i_{\text {Passive }}}\right)-\operatorname{RMS}\left(X_{i_{\text {Controlled }}}\right) .}{\operatorname{RMS}\left(X_{i_{\text {Passive }}}\right)} .
\end{aligned}
$$

4.3.1. Road Profile with Bump Test. For this test, two variables are important: (1) vertical acceleration of the sprung mass $\left(\ddot{z}_{s}\right)$, Figure 14(a), and (2) pitch angle $(\phi)$, Figure 14(b). For the vertical acceleration, Figure 14(a), the GCC system achieves $9.6 \%$ of improvement in vibration mitigation when compared with the reference case (UC); on the other hand the DC case achieves $3.11 \%$. During this test the bump it intended to excite the pitch motion of the vehicle, which is also related to the comfort of the passengers, Figure 14(b); the GCC system manages to reduce the pitch motion of the vehicle by $11.7 \%$ whereas the DC case achieves $10.8 \%$, both results when compared with the UC case. The main improvement of the control strategy can be seen after the bump (1 second mark); during that transient response the vehicle reaches a stable behavior faster than the reference case.

4.3.2. Braking Distance Test. Two variables are the most important for this test: (1) brake distance, Figure 15(a), and 


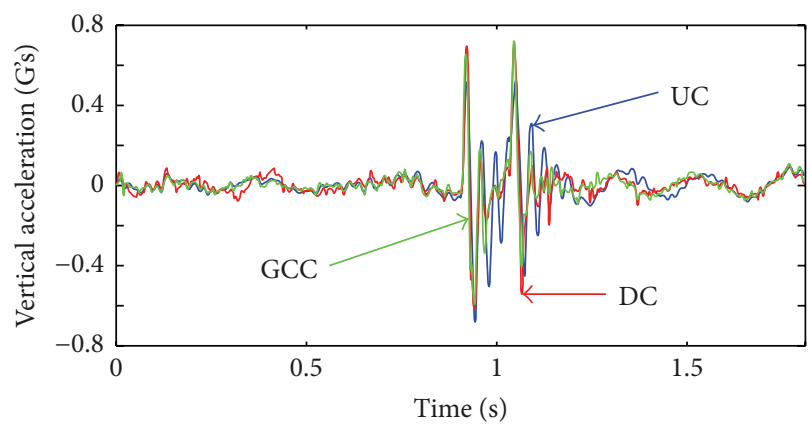

(a) Vertical acceleration $\left(\ddot{z}_{s}\right)$

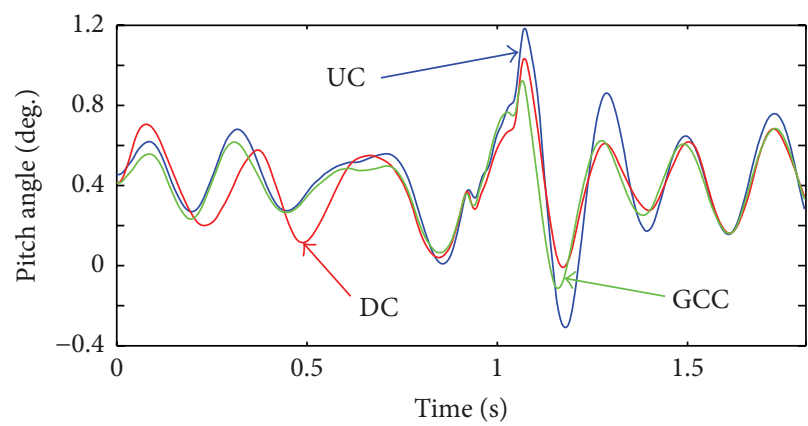

(b) Pitch angle $(\phi)$

FIGURE 14: Road profile with bump test.

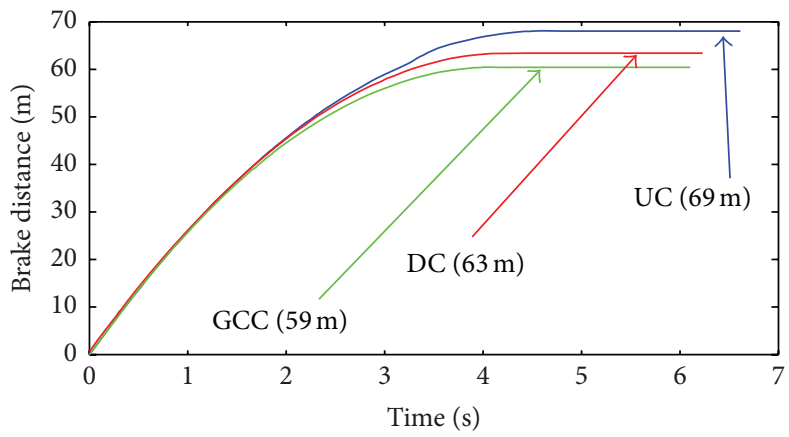

(a) Brake distance

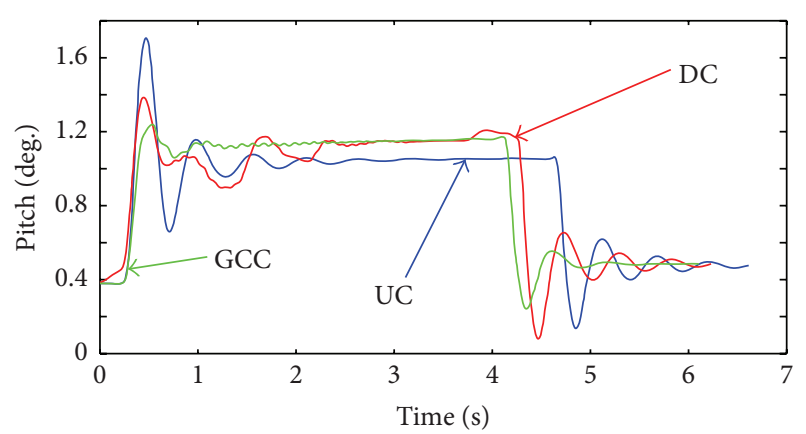

(b) Pitch angle $(\phi)$

FIGURE 15: Brake distance test.

(2) pitch angle $\phi$, Figure 15(b). Regarding brake distance, the reference case (UC) takes $69 \mathrm{~m}$ to fully stop, whereas the controlled cases have improvements of $8.7 \%$ for the DC and $14.5 \%$ for the GCC, meaning a stop distance of $10 \mathrm{~m}$ less than that of the UC case. For the pitch angle, the improvement of the DC against the UC was 6.2\%; whereas GCC has an improvement of 10.3\%. Also, in Figure 15(b) it can be seen that the GCC has less overshoot and shorter stabilization time. Those oscillations cause loss of grip of the tires and produce uncomfortable movements for the passengers. Even when the improvement indices for both controlled cases are marginal for the pitch angle, the uncomfortable behaviors are successfully attenuated.

4.3.3. DLC Test. Figure 16 shows the vehicle trajectory for each case. It can be observed that the GCC has the smallest $y$-coordinate deviation, and also its finish is straight, whereas for the UC the $y$-coordinate deviation is bigger and at the end its path is diverging. The DC has a performance similar to the $\mathrm{UC}$, but at the end the $y$-coordinate deviation is bigger (more negative) than the other cases.

After assessing the vehicle trajectory, it is important to analyze the behavior of the related variables to the vehicle stability, such as roll angle $(\theta)$, Figure 17(a), and yaw angle $(\psi)$, Figure 17(b). Figure 17(a) illustrates that the GCC system has less roll movement than the other cases, that is, $10 \%$ less than UC; also the roll movement has less duration having

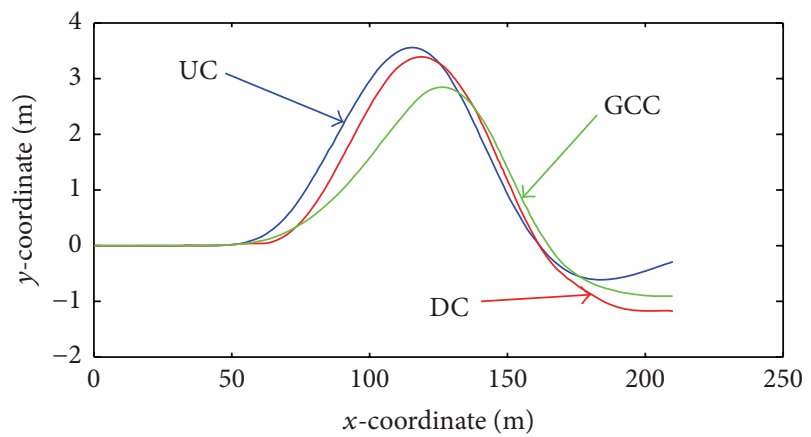

FIGURE 16: Vehicle trajectory for a DLC test.

a rapid stabilization. For the DC the roll movement is abruptly caused by the lack of coordination of the steering and braking; this causes those oscillations and a deterioration of $8.9 \%$ compared to the UC case. In Figure 17(b) also the GCC system has less yaw motion, $12.5 \%$ less than the UC, while the DC has a deterioration of $4 \%$ compared to the UC case.

4.3.4. FH Test. In this test, the evaluation starts with the assessment of the vehicle trajectory. Figure 18 shows the trajectory for the three cases. As it can be seen, the GCC system has a smaller turn radius than the other two cases, especially when compared with UC; this indicates more 


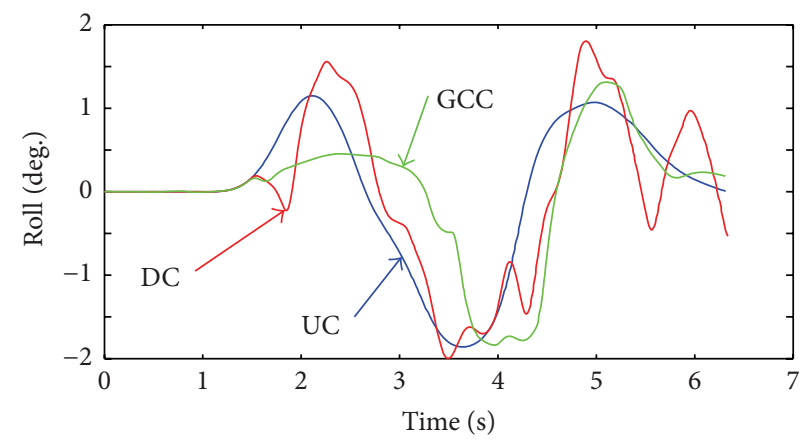

(a) Roll angle $(\theta)$

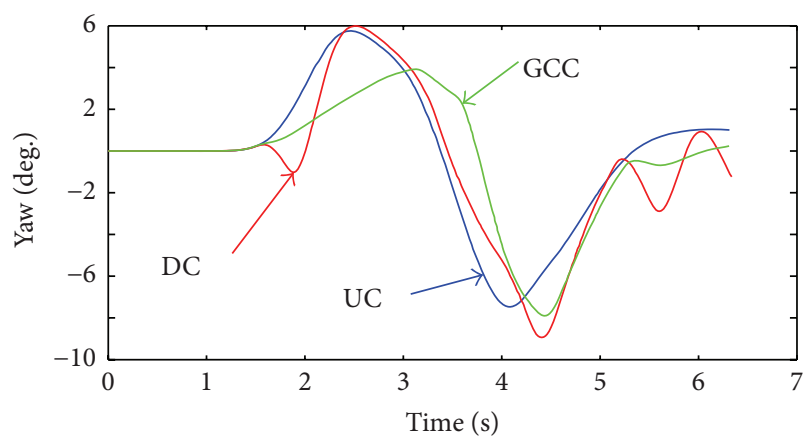

(b) Yaw angle $(\psi)$

Figure 17: DLC test.

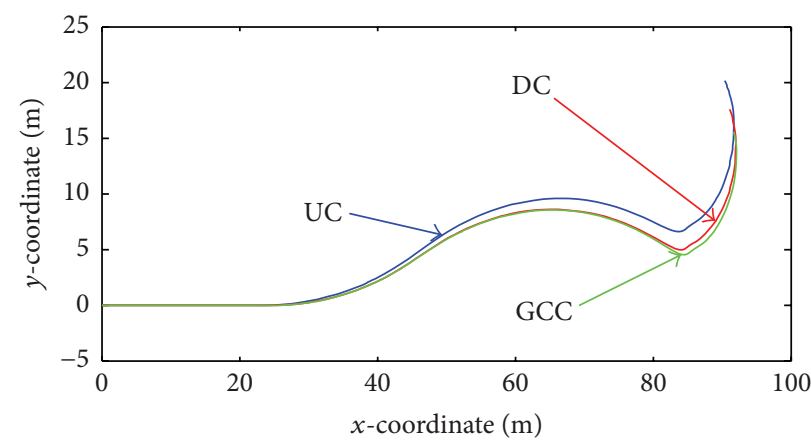

FIGURE 18: Vehicle trajectory for FH test.

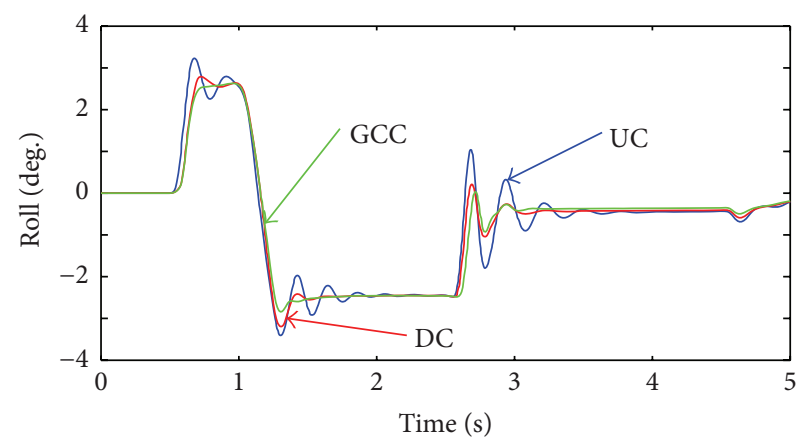

(a) Roll angle $(\theta)$

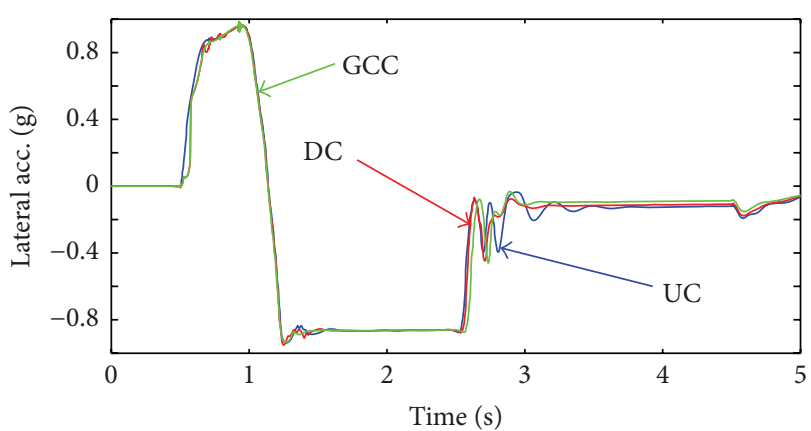

(b) Lateral acceleration $(\ddot{y})$

Figure 19: FH test.

handling capabilities in GCC. Also, the proposed GCC has a shorter trajectory, which indicates less skidding than other cases.

The significant variables are (1) roll angle $(\theta)$, Figure 19(a), and (2) lateral acceleration ( $\ddot{y})$, Figure 19(b). Since the induced cornering situation by the steering movement is really similar regardless of the control system, the important features to study are the transient responses of the variables at the time when the cornering starts and ends. From Figure 19(a) it is evident that in GCC the induced oscillations by the change of load transfer are better absorbed by the suspension system, that is, $7 \%$ less oscillations than in the UC case and 3\% less than in DC. Regarding lateral acceleration, Figure 19(b), GCC has less oscillations when the change of load takes place, even when the improvement is marginal: $2 \%$ with respect to UC. There is no significant improvement with respect to DC.

4.3.5. Split $\mu$-Surface Test. This test is designed to evaluate the ability of a vehicle to remain in control against a critical situation. It is important to verify how well the vehicle remains in its original path after the braking action starts. Figure 20 shows the trajectory of the three Vehicle Control Systems. The controlled vehicle with GCC remains in straight line during the whole test, whereas UC moves away from the original trajectory. On the other hand, the vehicle with DC also manages to remain close to the straight path. 


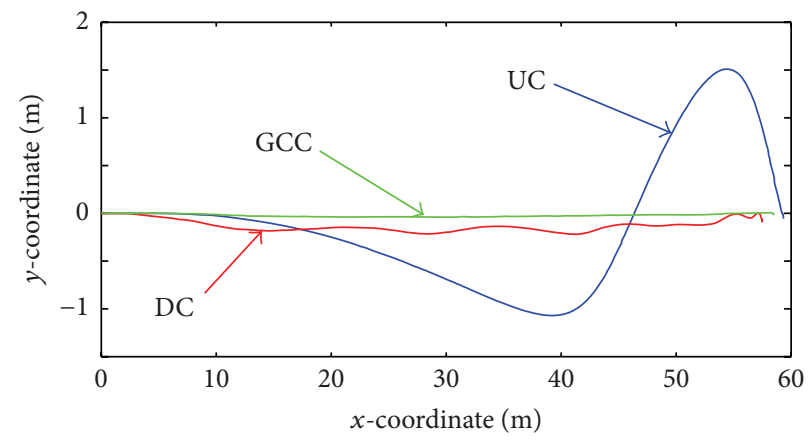

Figure 20: Vehicle trajectory for Split $\mu$-surface braking test.

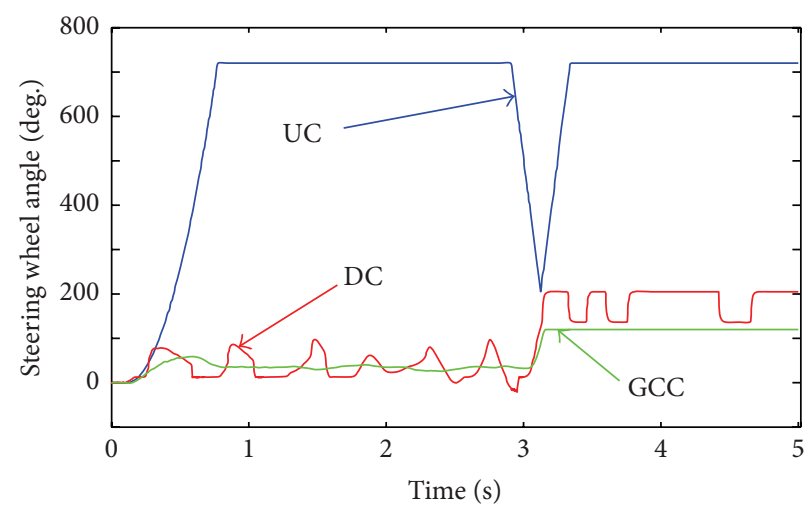

(a) Steering wheel angle $(\delta)$

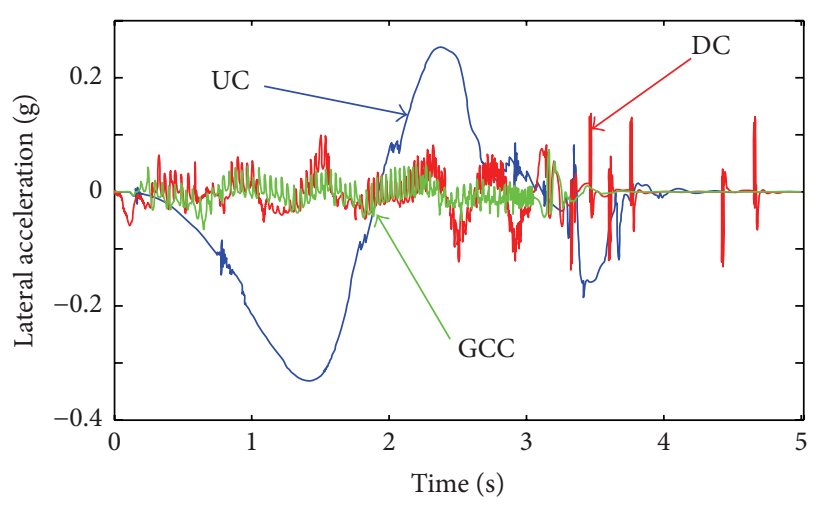

(b) Lateral acceleration ( $\ddot{y})$

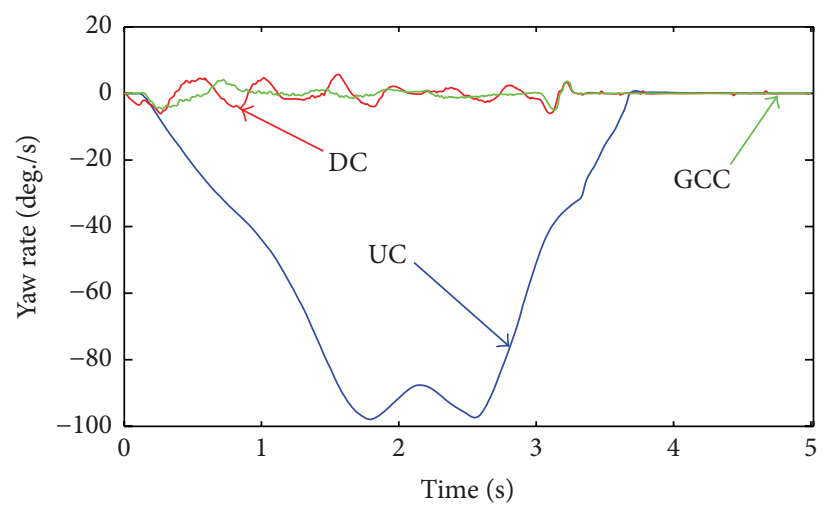

(c) Yaw rate $(\dot{\psi})$

FIGURE 21: Split $\mu$-surface braking test.

The important variables for this test are (1) steering wheel angle $(\delta)$, Figure 21(a), (2) lateral acceleration $(\ddot{y})$, Figure 21(b), and (3) yaw rate $(\dot{\psi})$, Figure 21(c). Figure 21(a) shows that the driver does not affect significantly the steering wheel angle, that is, the GCC and DC approaches can stabilize the vehicle. On the other hand, the UC vehicle begins to lose control and the driver has to make a huge adjustment to try to keep the stability of the vehicle. It can be noticed that the steering allocation system takes action increasing the steering maneuver for DC; this extra movements cause the vehicle to diverge slightly from the original path. The steering action for GCC is $87.9 \%$ less than UC vehicle, while DC has $80.6 \%$ less movement. Because the lateral acceleration is induced by the steering action, similar results are obtained, Figure 21(b). GCC has $88.7 \%$ less lateral acceleration than UC and $10.1 \%$ less acceleration than DC.

Finally, to evaluate the rotational movements of the vehicle in the road, the yaw rate is analyzed. Figure 21(c) shows that in UC the driver loses completely the vehicle control causing too much yaw motion. GCC has $98 \%$ less yaw rate than UC and $96 \%$ less than DC.

\section{Conclusions}

A novel Global Chassis Control system was proposed. It combines fuzzy logic inference systems, data-based logic and 
heuristic techniques as classifiers, allocation systems, and model-free controllers; also, it takes the advantages of a priori knowledge of a vehicle driving to develop an efficient control strategy. Also, it has the advantage of being modular and computationally light; based on Principal Components Analysis data reduction was applied. Most of the computing is done offline; the onboard systems only execute the classification of the driving situations and calculate the allocation and control procedures.

The evaluation of the strategy was performed with several well-known tests using CarSim. Simulation results showed that the performance of the Global Chassis Control system outperforms the uncontrolled vehicle case and the Decentralized Controllers scheme that do not have coordination features. Qualitative and quantitative results of the evaluation demonstrate the importance of a coordination level when different controllers coexist and interact in an integrated system as a vehicle. Such coordination level consists in a classification algorithm, based on the $k$-Nearest Neighbor clustering technique, supported by a Suspension Adjustment Plane to identify different driving situations.

\section{Conflict of Interests}

The authors declare that there is no conflict of interests regarding the publication of this paper.

\section{Acknowledgments}

The authors thank Tecnológico de Monterrey and CONACyT for their partial support through the Automotive Consortium research chair and PCP 03/10 and 06/13 bilateral (MéxicoFrance) projects.

\section{References}

[1] H. Chou and B. D’Andréa-Novel, "Global vehicle control using differential braking torques and active suspension forces," Vehicle System Dynamics, vol. 43, no. 4, pp. 261-284, 2005.

[2] S. Drakunov, U. Ozguner, P. Dix, and B. Ashrafi, "ABS control using optimum search via sliding modes," IEEE Transactions on Control Systems Technology, vol. 3, no. 1, pp. 79-85, 1995.

[3] TechCast, "Bubble charts of TechCast's latest results on TRANSPORTATIONs,” Tech. Rep., TechCast-LLC, 2012.

[4] WHO, "Global status report on road safety 2013: supporting a decade of action," Technical Report, World Health Organization, 2013.

[5] C. J. Kahane, "Lives Saved by vehicle safety technologies and associated federal motor vehicle safety standards, 1960 to 2012 passenger cars and LTVs with reviews of 26 FMVSS and the effectiveness of their associated safety technologies in reducing fatalities, injuries, and crashes," Tech. Rep., National Highway Traffic Safety Administration, Washington, DC, USA, 2015.

[6] F. Yu, D.-F. Li, and D. A. Crolla, "Integrated vehicle dynamics control-state-of-the art review," in Proceedings of the IEEE Vehicle Power and Propulsion Conference (VPPC '08), pp. 1-6, Harbin, China, September 2008.

[7] N. Schilke, R. Fruechte, N. Boustany, A. Karmel, B. Repa, and J. Rillings, "Integrated vehicle control," in Proceedings of the
International Congress on Transportation Electronics, pp. 97-106, Dearborn, Mich, USA, October 1988.

[8] T. El-Sheikh, Concept of global chassis control: using model reference and virtual actuators [Ph.D. thesis], University of California, Oakland, Calif, USA, 2011.

[9] J. He, Integrated vehicle dynamics control using active steering, driveline and braking [Ph.D. thesis], University of Leeds, Leeds, UK, 2005.

[10] M. Valasek, O. Vaculin, and J. Kejval, "Global chassis control: integration synergy of brake and suspension control for active safety," in Proceedings of the 7th International Symposium on Advanced Vehicle Control, pp. 495-500, Arnhem, The Netherlands, 2004.

[11] P. Gáspár, Z. Szabó, J. Bokor, C. Poussot-Vassal, O. Sename, and L. Dugard, "Global chassis control using braking and suspension systems," in Proceedings of the 20th Symposium of the International Association for Vehicle System Dynamics, pp. 13-17, Berkeley, Calif, USA, August 2007.

[12] R. D. Fruechte, A. M. Karmel, J. H. Rillings, N. A. Schilke, N. M. Boustany, and B. S. Repa, "Integrated vehicle control," in Proceedings of the 39th IEEE Vehicular Technology Conference: Gateway to New Concepts in Vehicular Technology, vol. 2, pp. 868-877, San Francisco, Calif, USA, May 1989.

[13] J. Andreasson and T. Bunte, "Global chassis control based on inverse vehicle dynamics models," Vehicle System Dynamics, vol. 44, supplement 1, pp. 321-328, 2006.

[14] O. Mokhiamar and M. Abe, "How the four wheels should share forces in an optimum cooperative chassis control," Control Engineering Practice, vol. 14, no. 3, pp. 295-304, 2006.

[15] W. Cho, J. Choi, C. Kim, S. Choi, and K. Yi, "Unified chassis control for the improvement of agility, maneuverability, and lateral stability," IEEE Transactions on Vehicular Technology, vol. 61, no. 3, pp. 1008-1020, 2012.

[16] M. Ali, P. Falcone, C. Olsson, and J. Sjöberg, "Predictive prevention of loss of vehicle control for roadway departure avoidance," IEEE Transactions on Intelligent Transportation Systems, vol. 14, no. 1, pp. 56-68, 2013.

[17] S. Sato, H. Inoue, M. Tabata, and S. Inagaki, "Integrated chassis control system for improved vehicle dynamics," in Proceedings of the International Symposium on Advanced Vehicle Control (AVEC '92), pp. 413-418, Yokohama, Japan, 1992.

[18] C. Poussot-Vassal, Robust multivariable linear parameter varying automotive global chassis control [Ph.D. thesis], Institut Polytechnique de Grenoble, Grenoble, France, 2008.

[19] S.-B. Lu, Y.-N. Li, S.-B. Choi, L. Zheng, and M.-S. Seong, "Integrated control on MR vehicle suspension system associated with braking and steering control," Vehicle System Dynamics, vol. 49, no. 1-2, pp. 361-380, 2011.

[20] S. Fergani, O. Sename, and L. Dugard, "Performances improvement through an $L P V=H_{\infty}$ control coordination strategy involving braking, semi-active suspension and steering Systems," in Proceedings of the 51st IEEE Conference on Decision and Control (CDC '12), pp. 4384-4389, Maui, Hawaii, USA, December 2012.

[21] T. Gordon, M. Howell, and F. Brandao, "Integrated control methodologies for road vehicles," Vehicle System Dynamics, vol. 40, no. 1-3, pp. 157-190, 2003.

[22] J. Nayak, B. Naik, and H. Behera, "Fuzzy C-means (FCM) clustering algorithm: a decade review from 2000 to 2014," in Computational Intelligence in Data Mining-Volume 2, L. C. Jain, H. S. Behera, J. K. Mandal, and D. P. Mohapatra, Eds., vol. 
32 of Smart Innovation, Systems and Technologies, pp. 133-149, Springer, 2015.

[23] P. Gáspár, Z. Szabó, J. Bokor, C. Poussot-Vassal, O. Sename, and L. Dugard, "Towards global chassis control by integrating the brake and suspension systems," in Proceedings of the 5th IFAC Symposium on Advances in Automotive Control, pp. 563-570, Pajaro Dunes, Calif, USA, August 2007.

[24] A. Tavasoli, M. Naraghi, and H. Shakeri, "Optimized coordination of brakes and active steering for a $4 \mathrm{WS}$ passenger car," ISA Transactions, vol. 51, no. 5, pp. 573-583, 2012.

[25] T. Raste, R. Bauer, and P. Rieth, "Global chassis control: challenges and benefits within the networked chassis," in Proceedings of the FISITA World Automotive Congress, Munich, Germany, 2008.

[26] W. Chen, H. Xiao, L. Liu, J. W. Zu, and H. Zhou, "Integrated control of vehicle system dynamics: theory and experiment," in Advances in Mechatronics, chapter 1, InTech, Rijeka, Croatia, 2011.

[27] R. P. Good, D. Kost, and G. A. Cherry, "Introducing a unified PCA algorithm for model size reduction," IEEE Transactions on Semiconductor Manufacturing, vol. 23, no. 2, pp. 201-209, 2010.

[28] R. Isermann, Fault-Diagnosis Systems, Springer, Berlin, Germany, 1st edition, 2006.

[29] B. L. Boada, M. J. L. Boada, and V. Díaz, "Fuzzy-logic applied to yaw moment control for vehicle stability," Vehicle System Dynamics, vol. 43, no. 10, pp. 753-770, 2005.

[30] S. Krishna, S. Narayanan, and S. D. Ashok, "Control of yaw disturbance using fuzzy logic based yaw stability controller," International Journal of Vehicular Technology, vol. 2014, Article ID 754218, 10 pages, 2014.

[31] S. Guo, S. Yang, and C. Pan, "Dynamic modeling of magnetorheological damper behaviors," Journal of Intelligent Material Systems and Structures, vol. 17, no. 1, pp. 3-14, 2006.

[32] M. Doumiati, O. Sename, L. Dugard, J.-J. Martinez-Molina, P. Gaspar, and Z. Szabo, "Integrated vehicle dynamics control via coordination of active front steering and rear braking," European Journal of Control, vol. 19, no. 2, pp. 121-143, 2013. 


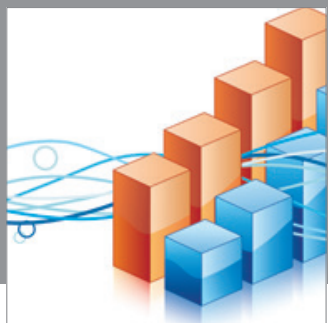

Advances in

Operations Research

mansans

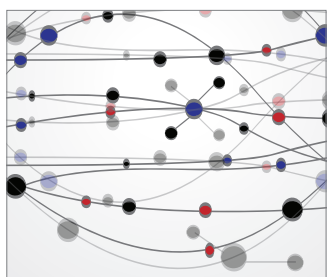

The Scientific World Journal
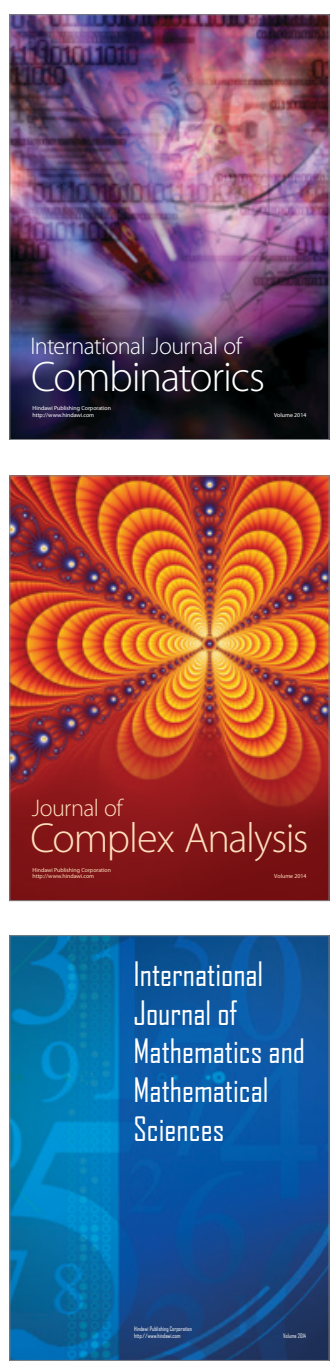
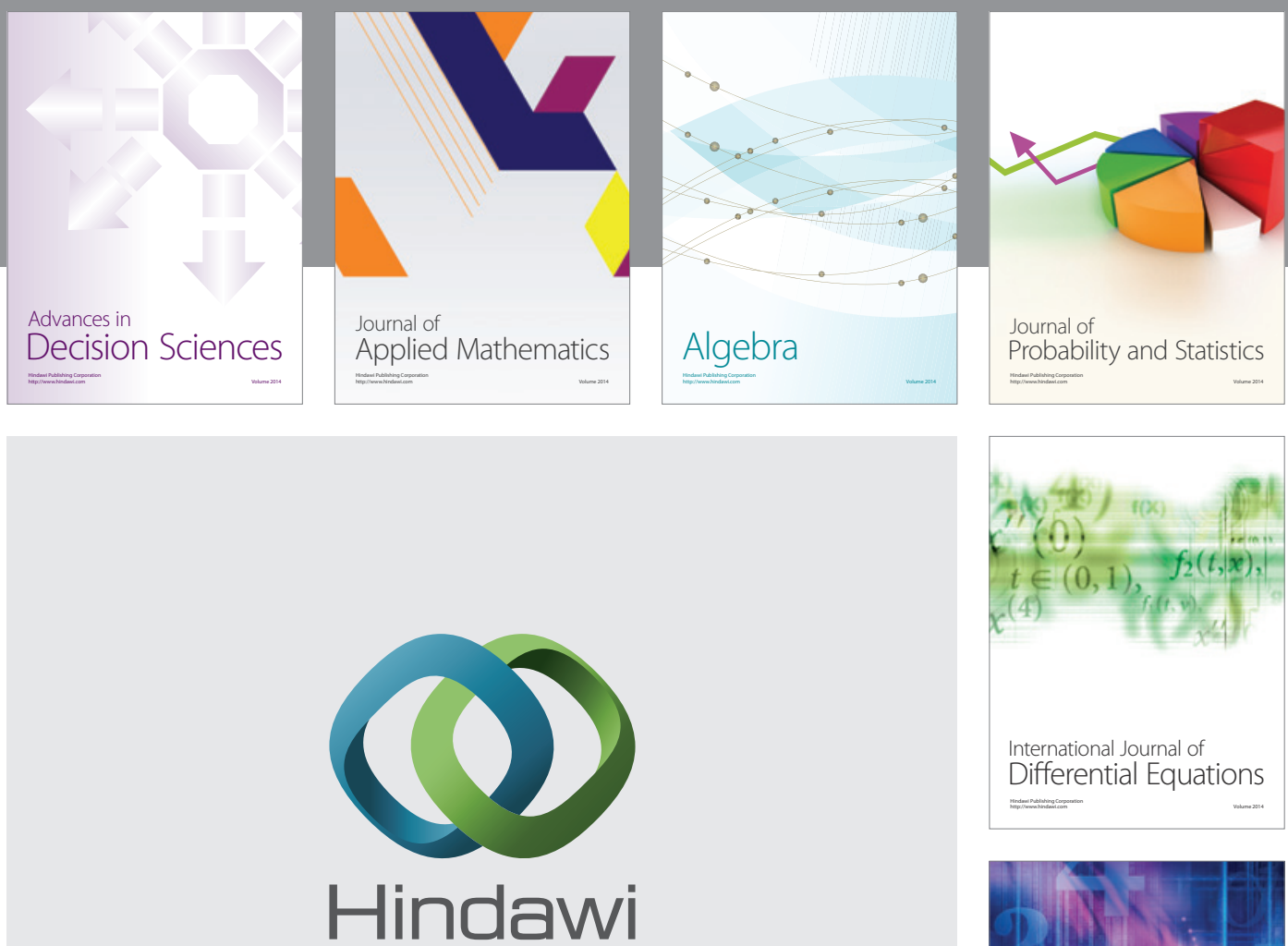

Submit your manuscripts at http://www.hindawi.com
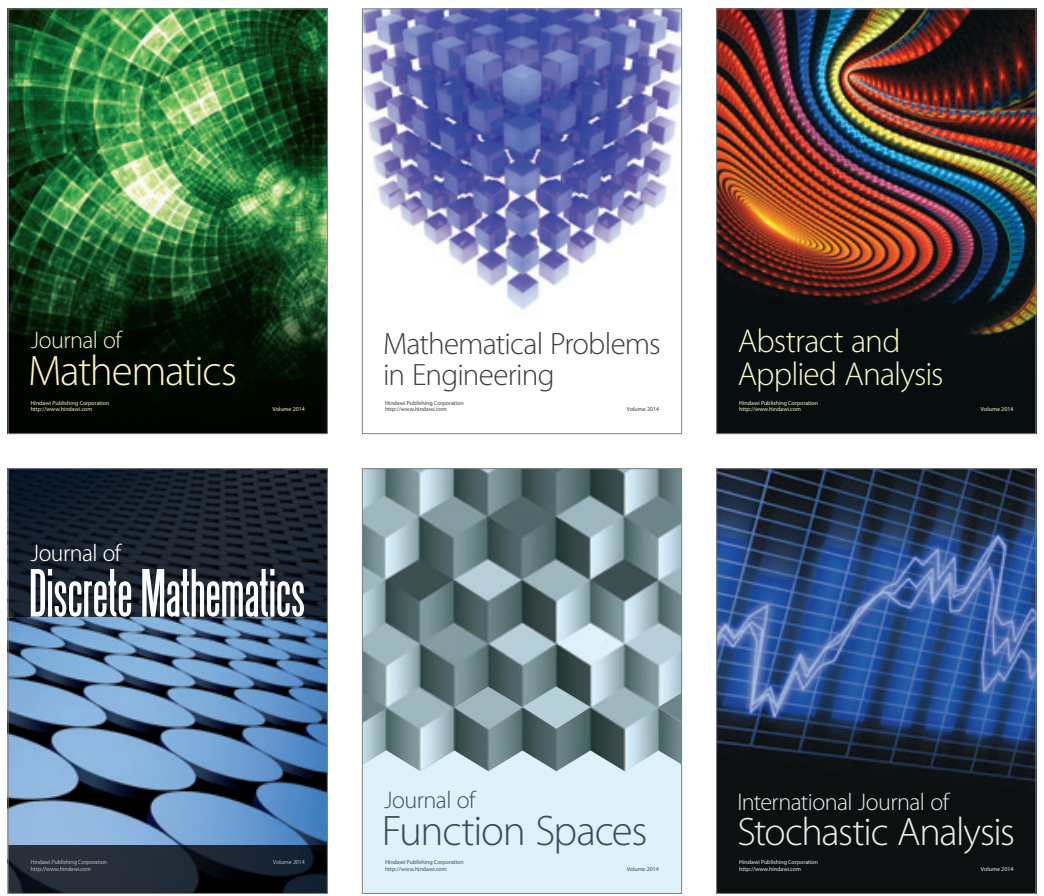

Journal of

Function Spaces

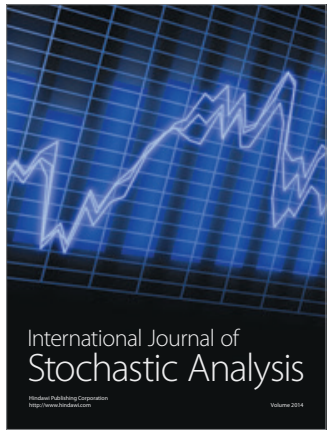

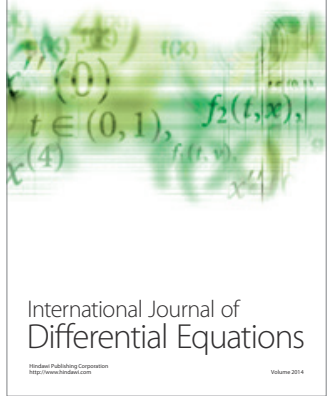
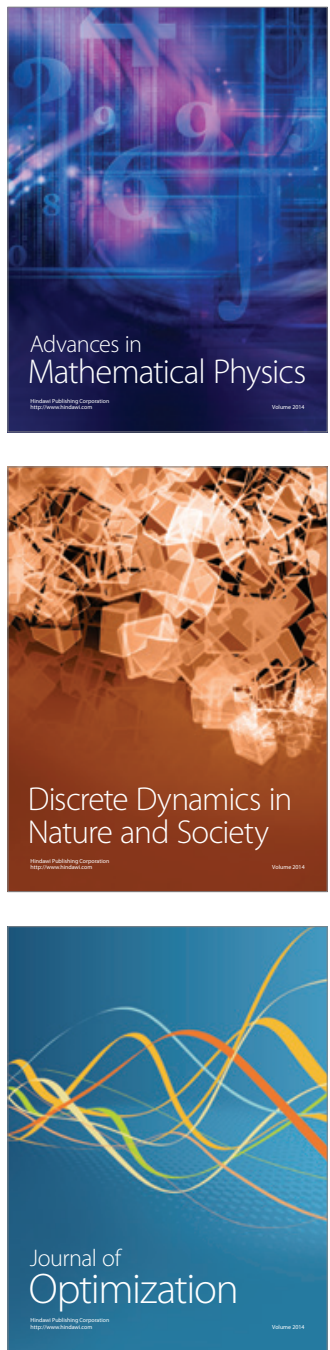